\title{
Assessment of cognitive instrumental activities of daily living: a systematic review
}

Dulce Romero-Ayuso, Álvaro Castillero-Perea, Pascual González, Elena Navarro, José Pascual Molina-Massó, M. Jesús Funes, Patrocinio Ariza-Vega, Abel Toledano-González \& José Matías Triviño-Juárez

To cite this article: Dulce Romero-Ayuso, Álvaro Castillero-Perea, Pascual González, Elena Navarro, José Pascual Molina-Massó, M. Jesús Funes, Patrocinio Ariza-Vega, Abel ToledanoGonzález \& José Matías Triviño-Juárez (2019): Assessment of cognitive instrumental activities of daily living: a systematic review, Disability and Rehabilitation

To link to this article: https://doi.org/10.1080/09638288.2019.1665720

View supplementary material $ָ$

曲 Published online: 24 Sep 2019.

Submit your article to this journal $₫$

Q View related articles $\asymp$

View Crossmark data 


\title{
Assessment of cognitive instrumental activities of daily living: a systematic review
}

\author{
Dulce Romero-Ayuso ${ }^{a}$, Álvaro Castillero-Pereab ${ }^{b}$ Pascual Gonzálezc, Elena Navarroc, José Pascual Molina-Massóc, \\ M. Jesús Funes ${ }^{d}$, Patrocinio Ariza-Vega ${ }^{a, e}$, Abel Toledano-González ${ }^{f}$ and José Matías Triviño-Juárez ${ }^{g}$ \\ ${ }^{a}$ Division of Occupational Therapy, Department of Physical Therapy, Faculty of Health Sciences, University of Granada, Granada, Spain; ${ }^{b}$ Faculty \\ of Health Sciences, University of Granada, Granada, Spain; 'LoUISE Research Group, Computing Systems Department, University of Castilla-La \\ Mancha, Albacete, Spain; ${ }^{\mathrm{d}}$ Mind, Brain and Behaviour Research Center (CIMCYC) and Department of Experimental Psychology, University of

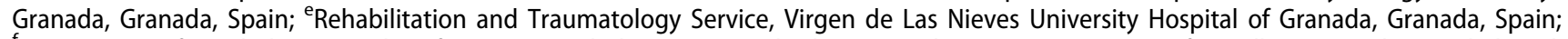 \\ fDepartment of Psychology, Faculty of Occupational Therapy, Speech Therapy and Nursing, University of Castilla-La Mancha, Ciudad Real, \\ Spain; ${ }^{9}$ Primary Care Center Zaidín Sur, Andalusian Health Service, Granada, Spain
}

\section{ABSTRACT}

Purpose: Cognitive instrumental activities of daily living are particularly related to executive functions, such as scheduling appointments, monthly payments, managing the household economy, shopping or taking the bus. The aim of this systematic review was to determine the available tests for the assessment of executive functions with ecological validity to predict individuals' functioning.

Materials and methods: An electronic search was conducted in MEDLINE, Cochrane Central, PsyCInfo and IEEE Xplore until May 2019, in addition to a manual search. The PRISMA criteria and the Covidence platform were used to select articles and extract data.

Results: After applying the search selection criteria, 76 studies were identified. They referred to 110 tools to assess instrumental activities of daily living. Those that have received most attention are related to menu preparation and shopping. Performance-based measures are the most widely used traditional methods. Most tests were aimed at the adult population with acquired brain damage, cognitive impairment or dementia. There was a predominance of tests based on the Multiple Errands Test paradigm.

Conclusions: In recent years, it has increased the number of tools that assess the instrumental activities of daily living based on technologies such as personal or environmental sensors and serious games.

> IMPLICATIONS FOR REHABILITATION

- Assessment of Instrumental Activities of Daily Living through performance-based measures is especially useful for the early detection of dysfunctions or preclinical disability.

- Difficulties in performing instrumental activities of daily living are closely associated with deficits in executive functions and prospective memory.

- Activities of Daily Living can be understood as multitasks.

- The use of virtual reality-based tests was shown to be sensitive to the detection of cognitive deficits in Activities of Daily Living.

- An advantage of using virtual reality in assessments is that it can help to predict the level of personal autonomy in patients who are in an institutional environment and could be a first approximation to the real environment.

\section{ARTICLE HISTORY}

Received 23 December 2018

Revised 3 September 2019

Accepted 5 September 2019

\section{KEYWORDS}

Activities of daily living; virtual reality; ecological validity; systematic review; executive functions

\section{Introduction}

Activities of daily living (ADLs) can be defined as the activities that people have to perform daily to be able to live in an autonomous way, be integrated in their usual environment and fulfill their social role [1]. The performance of activities of daily living also contributes to develop a sense of positive competence, self-efficacy, self-confidence and self-esteem when responding to various demands of the environment [2]. ADLs require motor, cognitive and socio-emotional skills. They can be classified as basic activities of daily living (BADLs), which refer essentially to personal care, or instrumental activities of daily living (IADLs), which involve a greater interaction with the social environment and higher cognitive demands. IADLs also are known as complex activities of daily living [3]. IADLs require less automatic actions than BADLs do [4].

According to the American Association of Occupational Therapy [5], 11 IADLs can be identified: (1) care of others, including the selection and supervision of caregivers; (2) care of pets; (3) child-rearing activities, involving the care and supervision of children; (4) communication management, involving the use of communication devices, such as mobiles, computers, tablets and others; (5) driving and mobility in the community, involving the use of public or private transport, transit through the community or neighborhood, and so on; (6) financial management, such as planning expenses and income to face daily or monthly payments, use of a cashier, electronic banking and similar activities; 
(7) health management and maintenance, such as maintaining a healthy routine, taking physical exercise, having adequate nutrition and annual health checkups, avoiding health risk behaviors and handling medication if necessary; (8) home establishment and management: for example, searching for a home and taking care of it, repairing clothes and personal belongings or cleaning the home; (9) meal preparation and cleanup: it includes planning a balanced and nutritious diet, cooking and cleaning after meals; (10) religious and spiritual activities and expression; (11) safety and emergency maintenance: knowing and developing processes to prevent accidents and responding to unexpected hazards or emergencies; and (12) shopping: it incudes making a shopping list, selecting the goods and payment method and purchasing the goods.

Two major factors have been differentiated in IADLs: (1) activities of daily living with a high physical demand; and (2) cognitive instrumental activities of daily living, such as scheduling appointments, organizing monthly payments or budgets, economic management of the monthly salary and similar activities $[6,7]$. Cognitive IADLs can be understood as everyday cognition, which has been defined as the ability to solve cognitively complex tasks of everyday life $[8,9]$ in the real world [10]. Recently, other authors have also referred to cognitive instrumental activities of daily living as functional cognition. This is understood as the performance of complex ADLs, which occurs thanks to the dynamic interaction of motor, cognitive and social skills, the demands of the activity and the context of performance of the activity [11]. These complex cognitive demands have led instrumental activities of daily living to be understood as multitasking skills, that is, skills involving various integrated cognitive processes and taking place in an unstructured context [12-14].

Burgess reported that multitasking activities have eight main characteristics [12]: (1) many tasks must be completed; (2) it is necessary to intersperse one task with another; (3) due to cognitive or physical limitations, only one task can be performed at a time, which sets them apart from the dual task paradigm, in which participants are instructed to perform two tasks at the same time; (4) unforeseen interruptions/unexpected results may occur; (5) the accomplishment of the different tasks requires prospective memory; (6) the different tasks vary in terms of priority, difficulty and duration; (7) the objectives of the tasks are defined by the person who is going to perform them; (8) and there is no continuous performance feedback during the performance of the task. Multitasking is related to a broad variety of cognitive functions and particularly to those associated with executive functioning and prospective memory. In this regard, it is easy to understand why IADLs have been mainly associated with cognitive components. Moreover, the performance of IADLs is sensitive to early cognitive decline $[15,16]$. Cognitive processes and particularly executive functions (EFs) are essential for the performance of IADLs [17]. Indeed, difficulties performing IADLs have been closely associated with deficits in executive functions, which increase the need to develop effective compensatory strategies to meet the demands of IADLs $[3,18]$. Deficits in executive functions are a predictor of participation and functional outcomes of various pathologies [19]; they occur in over $66 \%$ of patients having had a mild stroke [20] and predict functional outcomes at three, six, nine and twelve months in stroke patients [21,22]. EF has been found to explain $37 \%$ of the variance of functional status in individuals with mild cognitive impairment, unlike other cognitive processes [23]. Among EFs, flexibility accounts for $63 \%$ of the variance of functional status, followed by inhibitory control (32\%), planning (25\%) and reasoning and initiation (11\% each) $[15,24]$.
Other authors have reported that self-regulation of behavior and attentional control are crucial determinants for the independent performance of IADLs [22]. Actually, executive dysfunction tends to be more easily observed in everyday life in non-routine situations, where self-regulation and self-initiation of activities are relevant, than in traditional neuropsychological tests $[25,26]$.

Standard cognitive tests do not usually assess multitasking skills; in fact, most assess a specific cognitive function in a wellstructured and controlled environment. Indeed, it has been argued that there is a double dissociation between standard cognitive measures and multitasking skills, suggesting that the brain processes of multitasking skills may be independent of those of laboratory tests evaluating isolated cognitive processes [27]. This has led to growing criticism about the lack of clinical/ecological validity of some tests aimed at assessing cognitive IADLs, either because they use self-reports as a methodology - and in some cases patients are not aware of their deficits - or because they use reports by others and there is a discrepancy between the reports of informants and actual performance [28].

It has also been observed that some of these tests do not make it possible to determine which underlying processes affect functional performance beyond functional mobility $[29,30]$. In this regard, Burgess [29] has suggested that most traditional neuropsychological tests alone are insufficient to evaluate ADLs because they try to split the functions into components without including multitasking or significant familiar environments [31]. Cognitive tests and executive functions are often performed with standardized instruments in structured environments, without distractions and under the supervision of a clinician, which does not reflect the complexity that characterizes behavior in everyday activities in the real world [25]. Standard cognitive laboratory tests may overestimate functional difficulties, since individuals can apply compensatory strategies in their daily life or show behavioral patterns that increase their functionality [32] because they are highly familiar with these tasks. The ecological perspective is useful and of great interest in the evaluation of the various cognitive processes when the aim is to determine the causes of limitations in participation in the various activities of daily living that occur naturally in the real world taking multitasking skills into account [33]. In this context, a test is considered to have ecological validity when it is able to predict functional behavior in everyday life [26,34,35]. Parsons [36] suggested four key criteria to ensure that evaluations have ecological validity. They are (1) correspondence: tasks must correspond to the relevant aspects of the real-world activity and environment; (2) representativeness: tasks must be representative of the people who perform them; (3) convenience: tasks must be about real-world situations and the test results should reflect and predict real world phenomena; and (4) relevance: tasks must be relevant from a neurocognitive point of view.

One of the main inputs clinicians usually need to know is the restrictions or limitations in functional capacity that are caused by a certain disease, disorder or deficit and, therefore, what impediments to the performance of ADLs it causes. To be able to predict future functioning and/or improve participation, independence and personal autonomy through an intervention program, it is essential to perform a comprehensive assessment to determine the patient's profile, strengths, weaknesses and needs [18]. Identifying difficulties in cognitive IADLs could reduce hospital admissions, use of emergency services and caregiver overload [3]. All these aspects highlight the importance of knowing what tests are available, whether they have ecological validity and how to determine any existing gaps; it is important to encourage the 
development of this type of assessments to predict their functioning in the real world and demonstrate their predictive value regarding personal autonomy.

Considering the criticisms about the lack of ecological validity of tests assessing executive functions from the traditional neuropsychological perspective, the aim of this systematic review was to determine what instruments with ecological validity are available to assess instrumental cognitive activities of daily living including executive functions.

\section{Materials and methods}

We conducted a comprehensive search of the literature between 2 May 2018 and 31 May 2019 to identify the ecologically-valid instruments available for assessing cognitive instrumental activities of daily living that conform to the PRISMA statement (see Figure 1). The review was registered in PROSPERO with code CRD42018111599.

The search was conducted in the following databases: MEDLINE, SCOPUS, Cochrane, IEEE Explorer and Psyclnfo. The search strategy included the MeSH terms ("Activities of Daily Living" AND "Executive Functions" OR "Everyday Executive Skills") AND ("assessment" OR "evaluation") AND ("ecological validity") in the title or abstract and articles published between 2014 and 31 May 2019.

\section{Inclusion criteria}

Studies reported in English and Spanish were included according to the following criteria:

- Design: systematic reviews and specific original articles on the assessment of activities of daily living.

- Participants: individuals with executive dysfunctions or with delays in the development of executive functions that affect their participation in activities of daily living regardless of their age;

- Intervention: assessments and tools with ecological validity aimed at identifying deficits in cognitive instrumental ADLs.

To determine when a test had ecological validity, we followed similar tests to those used by Chevignard et al. [37]:

- Tests requiring the performance of a multitasking, openended activity in a naturalistic environment or a virtual environment simulating a naturalistic environment.

- Questionnaires focused on the performance of cognitive instrumental activities of daily living.

The inclusion of articles comprised two stages. In the first stage, we selected systematic reviews and original articles on the
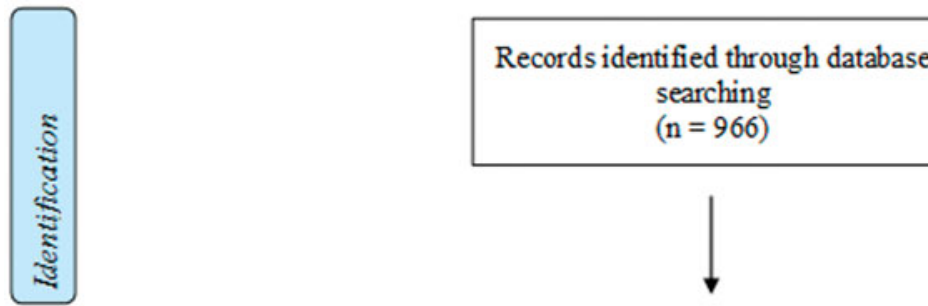

Records identified through database searching $(\mathrm{n}=966)$

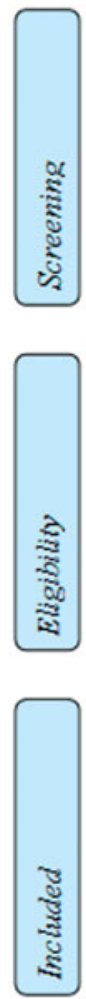

Studies included in

qualitative synthesis $(n=76)$
Records once duplicates were removed $(n=428)$

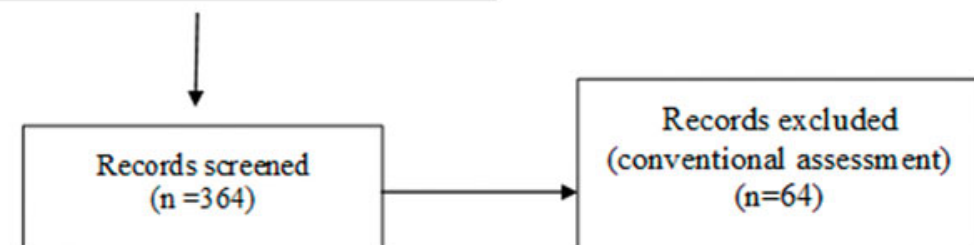

Full-text articles excluded, with reasons (articles that did not use tests with ecological validity were excluded, traditional experimental tests) $(n=27)$

Figure 1. Prisma 2009 Flow Diagram. 
evaluation of executive functions from an ecological perspective, considering the impact of such functions, that is, how they affected participation in instrumental cognitive activities of everyday life. In the second stage, if necessary, a specific search was made of each instrument or assessment task used to determine its psychometric properties and other possible applications.

\section{Exclusion criteria}

The following studies were excluded:

- Questionnaires that only included the performance of IADLs without considering the underlying executive processes (e.g., Functional Activities Questionnaire [38] and questionnaires that only focused on executive functions (e.g., Dysexecutive Questionnaire [29].

- Tests that evaluated executive functions but did not do so from an ecological perspective or in relation to IADLs (e.g., Ball Search Field Task [39].

- Tests or tasks that only focused on one cognitive process, such as prospective memory (e.g., the Virtual Week Task, [40,41], Prospective Execution Task [42] or Virtual Environment Grocery Store [43]) or other cognitive processes such as prospective memory or spatial orientation, even if it was in an everyday environment (e.g., EXPANSES, Episodic, Museum Task/Virtual Make [44], tests of everyday action semantics [45], Allen Cognitive Level Screen, (ACLS-5/LALCs5) [46], Picture Interpretation Test, or solving problems in everyday life (Everyday Problems Test).

- Virtual tests performed in everyday scenarios but aimed at measuring only one cognitive process, such as inhibitory control (e.g., Virtual Apartment Stroop Task, [47] Virtual Reality Moral Dilemma Scenarios [48], Virtual Anticipating Consequences Task [49]; Beach/Sorting beach apparel and refreshments [50] with no multitasking demands.

- Narrative reviews, letters to the editor, dissertations and articles that were not peer-reviewed.

\section{Identification and selection of studies}

The Covidence platform was used to identify and select the studies (https://www.covidence.org/home). Initially, duplicates were removed from the total of identified articles. Two authors reviewed the remaining article titles and abstracts to determine whether they met the inclusion criteria. Next, an independent reviewer screened the articles that had not been selected to ensure they should be excluded. Any article eliciting doubts or disagreement was fully reviewed by the independent reviewers until a decision was finally reached on its inclusion or exclusion (see Figure 1 for a flow diagram adapted from the PRISMA methodology).

Once the measures, scales or tasks had been identified, a second electronic search was performed in the same databases. This search was performed using the full name of the measures in order to obtain the psychometric properties of each instrument.

\section{Data collection and methodological quality of studies}

A data extraction sheet was developed and the data collection included the name of the instrument, the executive function dimensions it assessed, the assessment methodology, the population to which it applied, the type of context in which the test was performed and its psychometric properties. For each eligible assessment tool, two researchers extracted all relevant data.
In case of disagreement, discussions were held to reach a consensus, with a third reviewer if necessary.

\section{Results}

The search yielded a total of 966 abstracts. Figure 1 shows both the selection process and how many articles were considered in each stage of the process. Of the 76 articles selected, we found references to 110 tools aimed at identifying the executive functions underlying IADLs. In order to broadly show the results found, they have been classified according to different dimensions. First, the instruments found for each type of instrumental activity of daily living are presented following the classification of ADL of the American Association of Occupational Therapy (see Table 1). Second, the different instruments are showed according to the methodology used for the evaluation of ADLs: (1) traditional methodologies, which include performance-based measures, behavior rating scales and self-reports; and (2) methodologies involving the use of technologies, such as virtual reality systems, serious games, environmental sensors and others. Third, the paradigms used for the evaluation of ADLs are presented: Performance-based naturalistic tasks, the Multiple Errands Test (MET) and the dual-task paradigm. The fourth section of the results shows the specific instruments that have been found for different clinical groups with cognitive, mental or neurodevelopmental problems. In addition, the available instruments for children, adolescents, adults and the elderly are compiled in each section. Overall, 32 of these tools were virtual or technological assessments, 20 were tests aimed at assessing cognitive IADLs in children or adolescents and 58 were tests aimed at assessing IADLs in adults or older people. Results also showed 11 performance-based measures for children or adolescents and 44 performance-based measures for adults or older people. In addition, there were six behavior rating scales and two self-reported measures for children or adolescents. There were eight behavior rating scales and four self-reports aimed at adults and older people. Only one of these instruments was a performance-based measure specifically aimed at adolescents; it was focused on planning activities (see Tables 1, Supplementary Table S1 and S2).

\section{Types of tests according to the type of IADLs}

As regards tests aimed at adults, most instruments assessed activities related to meal preparation and cleanup, followed by activities related to financial and communications management, health management and maintenance, mobility in the community and shopping (see Figure 2).

In children and adolescents, the IADLs assessed by most instruments were related to other types of activities not classified according to the American Occupational Therapy Association. Some examples are academic activities, which in some cases were related to communication skills, such as writing. There were also instruments aimed at assessing the skills for the planning of daily activities such as organizing a party. Of the IADLs classified by the American Occupational Therapy Association, the most frequent ones were meal preparation and cleanup, activities related to tidying up clothes and maintaining order at home (i.e., home establishment and management) and community mobility (i.e., assessing the skills of deciding when to cross the street or not in children with autism).

Regarding virtual tasks, the most numerous ones were aimed at shopping, money management and community mobility activities, followed by meal preparation and cleanup and 
ASSESSMENT OF COGNITIVE INSTRUMENTAL ADL $\div 5$

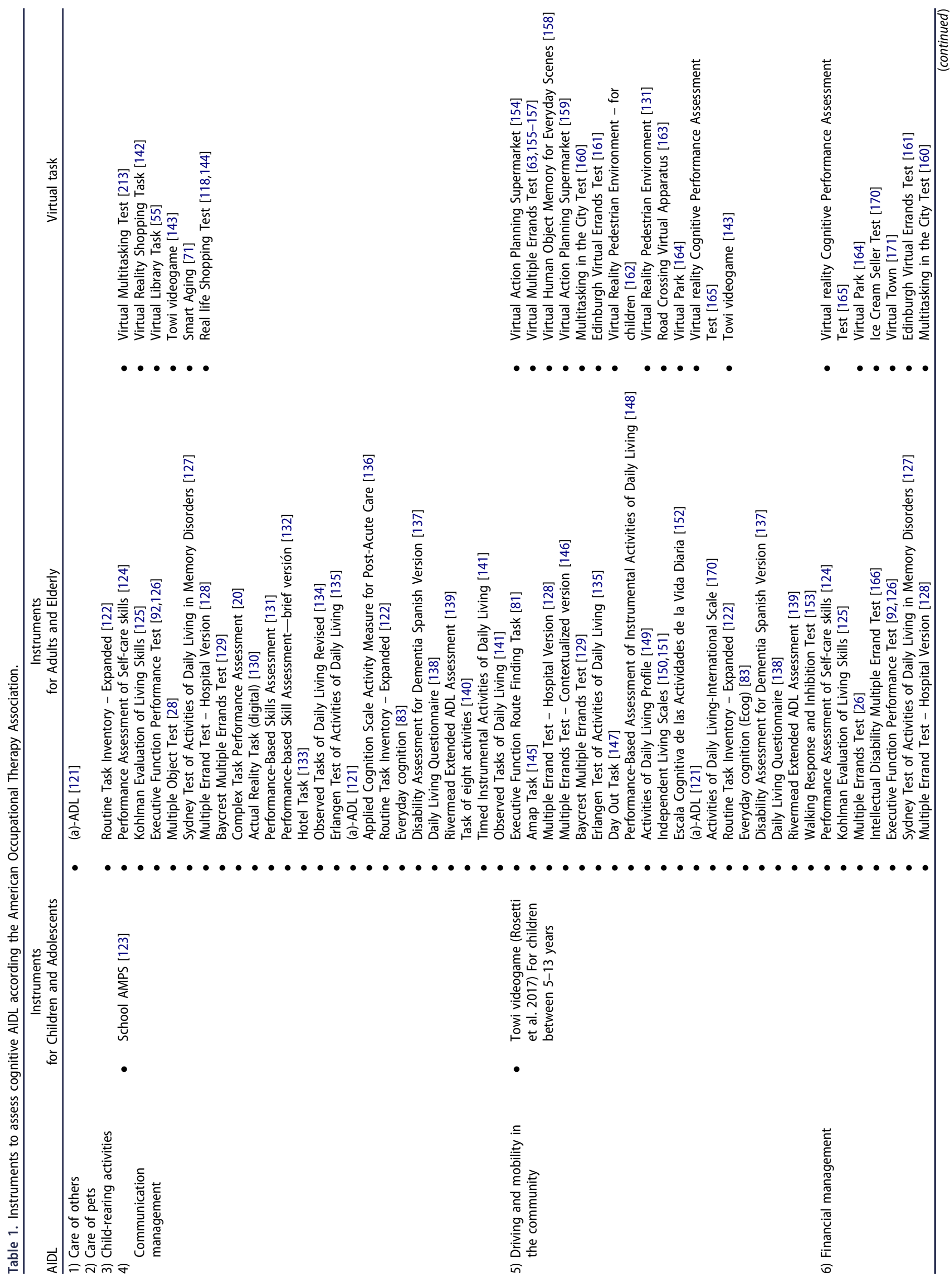


6 D. ROMERo-Ayuso et AL.

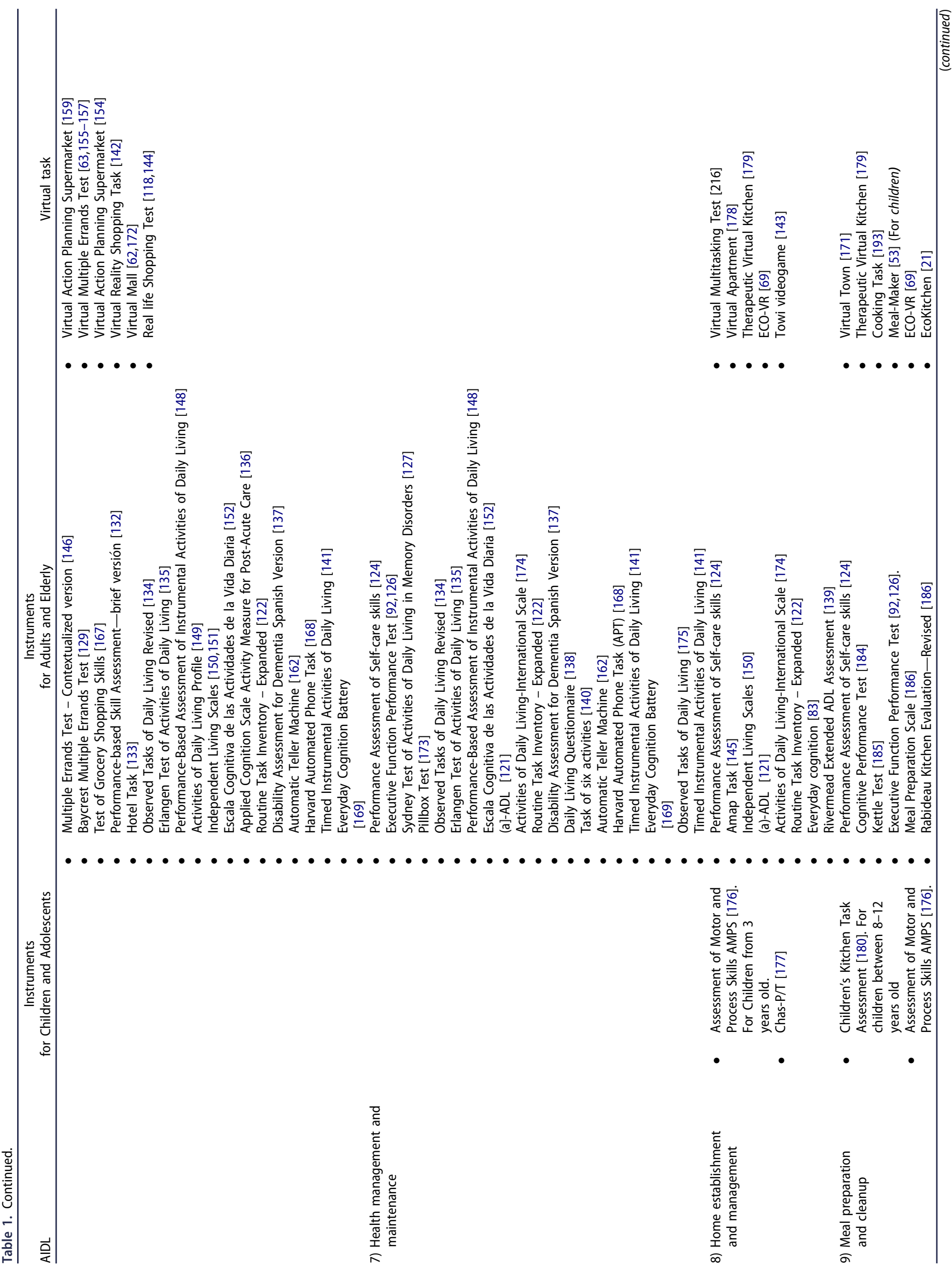




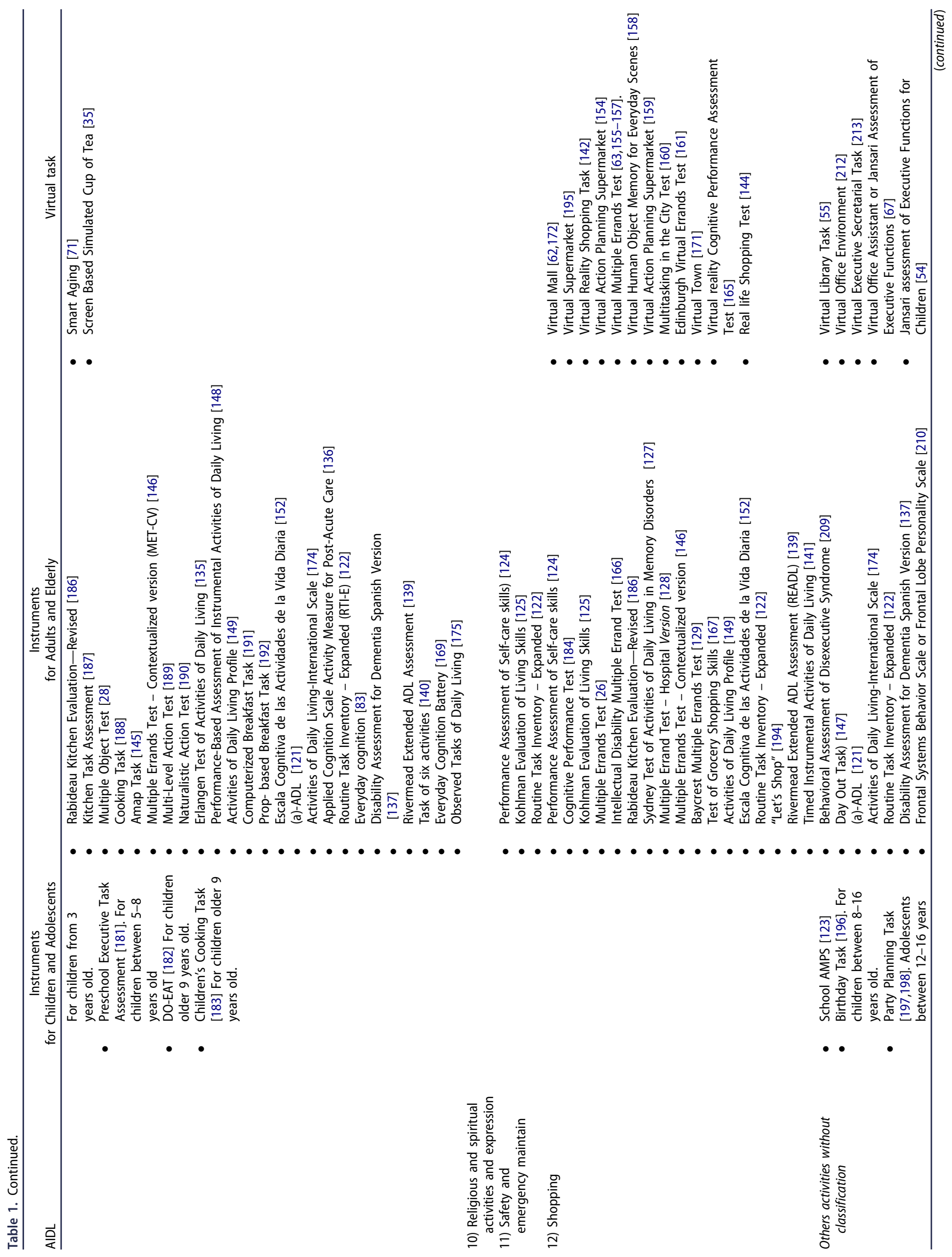


8 D. Romero-Ayuso et al.

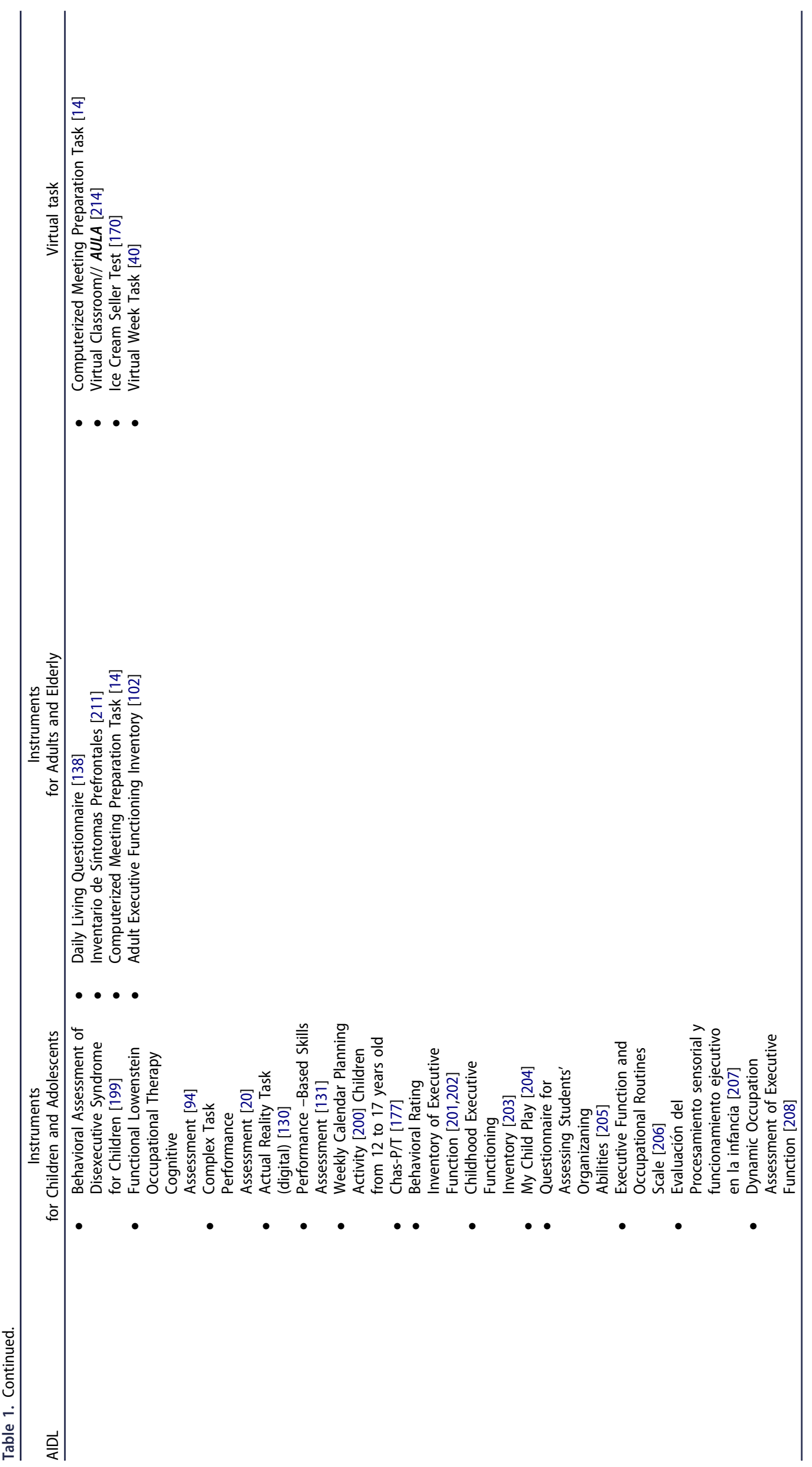


communications management. There were no virtual tasks for activities such as care of others, care of pets, child-rearing activities, religious or spiritual activities or safety and emergency maintenance.

\section{Types of instruments according to the methodology used}

Regarding the methodology used, we distinguished two major types of assessment methodologies: (1) traditional methodology and (2) technology-based instruments (e.g., virtual tasks, serious games, sensors) (see Supplementary Table S2 and S3). Several traditional methodologies have been used to assess IADLs: performance-based measures, behavior rating scales and self-reports. These methodologies correspond to three different perspectives: (1) tests aimed at assessing executive functions and determining their correlation with certain daily activities; (2) questionnaires or behavior rating scales of ADLs to determine the level of independence and support required, generally through proxies; and (3) performance-based measures aimed at identifying the underlying cognitive functions, especially executive functions and prospective memory through naturalistic tests and multitasking tests.

As regards virtual tasks, we found six tools for children, 26 for adults and only two for older people (see Figure 2, Supplementary Tables S1-S3). Results showed two types of systems using virtual reality to assess multitasking skills: 13 were based on virtual multiple errand tasks (i.e., shopping, community mobility and cooking) and 11 were based on the virtual office environment. Supplementary Table S3 summarizes the results, types of tasks and virtual scenarios found that made it possible to assess executive functions from an ecological perspective. The table shows the type of IADLs considered, the executive functions domain and the target population.

We found only one virtual global cognitive functioning assessment that addressed several daily activities (ECO-VR). As regards age, results showed only four virtual scenarios for children: two for children with ADHD, one for children with cerebral palsy and a test for adults adapted to children with executive dysfunction (Jansari Assessment of Executive Functions for Children). Two studies that used virtual reality to assess cognitive functions in children included the virtual classroom (AULA). AULA has been used to detect attention and inhibition deficits in children with attention hyperactivity deficit disorder [51] and acquired brain injury [52]. Another task supported by virtual reality that was developed for children is Meal-Maker, which involves preparing a menu [53]. In this case, the system collects information about the gestures and number of mistakes made by children with cerebral palsy, who show limitations in their movement. The Jansari assessment of Executive Functions for Children [54] is another specific virtual task designed to assess executive functions. In this task, the virtual scenario is a house with three bedrooms and a garden where children have to prepare a birthday party. They must organize it according to an instruction sheet that collects information about the guests and a letter from their parents with pending tasks to be performed.

Regarding adults and virtual reality, most evaluations were based on the Multiple Errands Test (MET). Six main virtual scenarios were identified. The Virtual Library Task [55] is a non-immersive virtual reality game and includes seven subtasks. In one of them subjects must perform several tasks following some preestablished rules, such as turning on the air conditioning in the library. In this case, when trying to turn it on, the machine warns them that it does not work so they have to solve the problem of cooling the library in a different way. The idea is to go to an adjacent room and pick up a fan there, take it to the library and turn it on. Other tasks are to photocopy three pages when there are only two pages available and not picking up the phone even though it is ringing, among others. Participants have between nine and $20 \mathrm{~min}$ to complete the task assigned, which can be assessed using the following factors: (1) analysis of the task; (2) generation of strategies and regulation; (3) prospective work memory; (4) inference and management of dual tasks; (5) inhibitory response; (6) prospective memory based on time; and (7) prospective memory based on events. The Multitasking in the City Test [56] is based on the same idea as the previously mentioned MET. In this case a virtual city is used. It includes a post office, drug store, stationary store, coffee shop, grocery store,

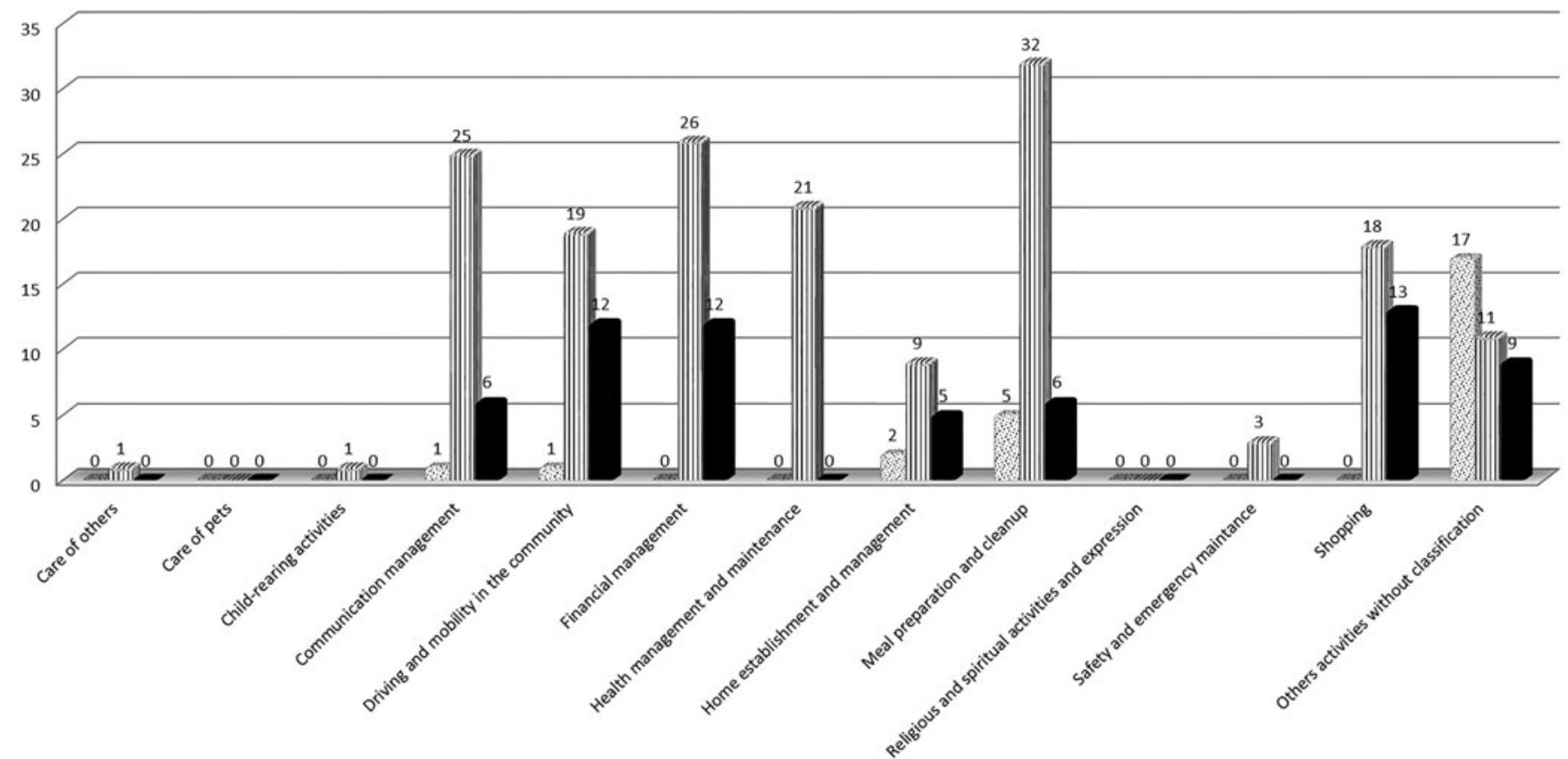

Figure 2. Instruments available for the assessment of the IADL. Instruments for children and adolescents . Instruments for adults and elderly serious games and new tecnological assessment 
optometrist's office, doctor's office, restaurant, bank, dry cleaners, pet store, and the participant's home. In this task participants must follow the following general rules: not traveling beyond a certain spatial boundary and not entering a store unless they intend to buy something, in order to explore behaviors that are not goal-directed. The Multitasking in the City Test was used to compare a sample of patients with acquired brain injury, a sample of patients with stroke and a sample of healthy individuals. This task revealed that the largest differences were found in the number of errors made by the clinical samples versus the healthy population. Other similar virtual tasks are the virtual city (Reh@City) [57], the virtual park and the virtual maze [58]. The last two scenarios were mainly used to assess orientation and spatial memory; the virtual maze was also used to assess trust and decision making [44].

Other virtual environments were used for the evaluation of ADLs such as shopping [59]; a few examples are the Virtual Action Planning-Supermarket [60], VMall [61,62] and the Virtual Multiple Errands Test [63].

In addition, using non-immersive systems, other studies included virtual tasks such as preparing coffee with an electric coffee maker $[64,65]$. They were developed to evaluate performance in IADLs, analyzing errors and validating them for populations with traumatic brain injury [65] and Alzheimer's disease [64]. Other virtual tasks related to community mobility were also developed, such as taking a bus [66]. Another type of instrument for measuring IADL in adults was the multitask known as the Jansari assessment of Executive Functions [67]. However, the activities to be performed were administrative and performed in an office (e.g., sending emails, preparing a room for a meeting).

Finally, there was also a battery (i.e., Systemic Lisbon Battery) aimed at assessing various cognitive processes using virtual reality. Specifically, it includes two tasks to assess executive functions: preparing breakfast and baking a cake [68]. The task of preparing breakfast required participants to use three ingredients in a certain sequence. To perform the second task, participants had to use five ingredients to bake the cake in the oven following a checklist. Another assessment tool that also includes both memory processes and executive functions is the ECO-VR task [69]. This task assesses five activities: watching the news on television; checking messages on an answering machine; organizing food and preparing the menu; finding items in a room; and remembering information related to TV news and the answering machine message.

In addition to virtual tasks, there were other methodologies used to evaluate ADLs by means of serious games platforms [70], combining game playing with a serious purpose such as that of assessing functional independence in older people through five ADL tasks in a family environment using the Smart Aging game [71]. Other types of assessments conducted with new technologies involve the use of sensors that collect data about participants' gestures, movements, location, interactions and actions [72]. For example, accelerometers are sensors that have been used to monitor the activity of getting dressed; magnetometers measure the strength of the magnetic field in three dimensions, provide guidance to users and detect and locate metallic objects within their detection radius. The location of the sensor (and of the person carrying it) can be determined based on its proximity to the objects detected. Finally, emerging studies are exploring the relationship between eye movement and changes in ocular fixation as predictors of cognitive and functional impairment [73].

\section{Types of tests according to the paradigm}

Some common aspects that must be considered in the tools available for the assessment of cognitive IADLs are the complexity of the activity, whether it requires a higher or lower level of attentional control, the subject's familiarity with the task (or its performance environment) and the novelty of the task. At least three paradigms can be found in this regard. Chronologically, the first paradigm is naturalistic tasks, which are performance-based measures. Performance-based naturalistic tasks are observable, rulebased, open tasks performed in an environment that mimics the real world or is the real world (e.g., in an apartment set up to conduct the assessment, a kitchen) $[74,75]$. As regards the instruments that use naturalistic tasks, we found three tests that used a cooking task in children (Children's Kitchen Task Assessment [52]; DO-EAT [56] and Children's Cooking Task [58] and one test aimed at preschool children (Preschool Executive Task Assessment) [55]. In addition, two instruments (i.e., Assessment Motor Process Skills and School- Assessment Motor Process Skills) were used while observing a significant activity of the child or adult, although intentional behavior, goal formulation or behavior monitoring were not among the executive functions considered. Furthermore, one instrument attempted to provide laboratory tasks with greater ecological value (Behavioral Assessment of Dysexecutive Syndrome), although it showed a low correlation with the behavior rating scale completed by parents and teachers. Supplementary Tables S2 and S3 show the tools found. The second paradigm is based on the Multiple Errands Test (MET). These tasks are multitasks that are oriented towards administrative or work-related activities such as working in an office. The Multiple Errands Test, with different variants, was the most frequently used multitask assessment. It involved tasks related to the hospital context, the therapeutic community or the supermarket (see Supplementary Table S1 and S2). This paradigm developed by Shallice and Burgess [75] attempts to address the limitations of common neuropsychology tests in identifying performancebased deficits in people with executive dysfunction. In addition to the MET paradigm and naturalist tasks, there is a paradigm of dual tasks, which combines walking and cognitive tasks (i.e., dualtask walking) [76]. This paradigm, exemplified by the Complex Task Performance Assessment, is a performance-based measure of executive functions developed from the MET and the action of the Supervisory Attentional System in complex multitasking situations [75]. The Complex Task Performance Assessment was designed to overcome the limitations of the MET in a clinical context [20]. An example of it is a task that simulates working in a library, which requires the completion of two tasks simultaneously: [1] control of current inventory and [2] telephone messaging.

\section{Types of tools according to the diagnosis}

There seem to be more tests aimed at older people, especially for the detection of cognitive impairment versus healthy aging, but most of them propose correlation studies between executive functions and ADLs. We identified 32 different tools.

A total of 22 different tests were found for adults with acquired brain injury. Eleven instruments were aimed at patients with schizophrenia, the most frequent of which were virtual tasks related to independence that were used in shopping activities such as the Test of Grocery Shopping Skills [77] and the Virtual Action Planning Supermarket [78] and pre-work activities such as the Computerized Meeting Preparation Task $[14,79]$. We found only three tests aimed at patients with addictive behaviors, one 
aimed at patients with orthopedic surgical pathology (AM-PAC) and one aimed at patients with obesity (Let's Shop), related to shopping behavior (i.e., compulsive or not, shopping patterns and items purchased). Other authors also explored the impact of cognitive processes in ADLs in patients with glioma in the temporal lobe [79].

\section{Discussion}

The purpose of this review was to provide an overview of the current state of the art of IADL assessments with ecological validity focused on executive functions. This study also intended to rapidly map the key concepts underpinning this research area and to identify the aspects that require further research to improve the assessment of independence in activities of daily living.

The emphasis on the search for neuropsychological tests with ecological validity is the result of a paradigm shift in neuropsychology evaluations from a localizationist perspective to one focused on the prediction of functioning in everyday life [36]. Traditional neuropsychology assessment techniques have focused on measuring cognitive deficits rather than functional skills [80]. An important differential characteristic between traditional neuropsychological tests and ADLs is that the latter imply a high level of control and the absence of interruptions, which does not happen in the real world $[81,82]$.

\section{Types of tests according to the IADLs}

It is possible to differentiate at least three types of approaches in the assessment of cognitive IADLs: (1) one essentially focuses on determining whether the person is independent or needs some kind of support for conduct ADL; (2) the second approach focuses on exploring the underlying cognitive processes in isolation and also in a highly controlled context with familiar materials; and (3) the third one is the result of merging the first two approaches to explore the underlying processes in the context of multistep/ multitask ADL performance.

Regarding the first approach, most assessments of ADLs have attempted to identify whether the person needs some kind of help - either as a verbal or physical support - for the performance of the activities, mainly through a reliable informant. Others have looked for errors due to failures in the attentional control that the patient can exert. Although these scales are helpful in quickly assessing the amount of support the person might need, they are completely unspecific about what causes their dependence. They do not even help to dissociate whether patients are dependent due to physical or cognitive deficits. Therefore, they are probably insufficient to guide clinicians to plan targeted treatments for a given patient.

Some of the disadvantages of self-reports is that, in patients with a lack of awareness of their deficits and/or mood changes, the reliability and validity of the data are reduced [74]. Similarly, the information obtained through a key informant (e.g., family member, caregiver) has the disadvantage of depending on knowledge about patients, the number of hours spent with them and the type of activities carried out with them [83]. This may lead to bias in the information obtained about the participation and performance of ADLs [84]. Behavior rating scales of executive functions such as Behavioral Rating Inventory of Executive Function, Childhood Executive Functioning Inventory and the "Evaluación del Procesamiento Sensorial y Funcionamiento Ejecutivo en la Infancia" have a clear structure that usually depends on the exploratory or confirmatory factor analysis. Executive deficits can be related to other processes such as prospective memory deficit or motor cognition, which are not always well differentiated in the questionnaires (i.e., behavior rating scales).

This systematic review focused essentially on performancebased tests for the evaluation of executive functions in everyday life. These results show a lack of instruments assessing people's independence in various cognitive IADLs (see Table 1). Results showed that the traditional tests and virtual tasks found either superficially considered some IADLs or failed to include them in the performance-based measures. Of the 11 IADLs described by the American Occupational Therapy Association, they only included the use of communication devices, financial management, health management and maintenance, community mobility and household management, and the preparation of menus [5]. The reason why there were no tools about the care of others or pets, child rearing and religious or spiritual activities may be that these types of activities are not general or carried out by the entire population, are more complex and can vary widely depending on the characteristics of the person or animal receiving the care. The same applies to driving activities. No driving assessments were found in this review either. This may be because driving is one of the most complex IADLs and has a specific assessment protocol [85]. Driving has also been strongly related to visual perceptual skills, motor skills and - when evaluated cognitively -, traditional neuropsychological tests such as the Montreal Cognitive Assessment, Clock Drawing Test, Useful Field of View test and Motor-Free Visual Perception Test and Trail Making Test $A$ and $B$ are used, among others. Specific tests to assess driving skills have been developed from the discipline of occupational therapy (e.g., OT-Driver Off Road Assessment, OTDORA [86], and STISIM Drive simulator and simulator protocol $[87,88])$.

In addition, it is important to consider that there are several instruments related to performance in educational and workrelated activities. In such activities, executive functions are essential and can be understood as instrumental activities since they are not conducted as an end in themselves but rather to achieve something (e.g., learning, earning a degree, obtaining an economic reward) [89].

One of the activities that have not been explored virtually is the evaluation of the maintenance of good health or use of medication, although there are different devices (e.g., apps) related to this activity for the general population, such as fitbit bracelets and accelerometers, among others. No scenarios assessed safety and response to emergencies both in the home and in other contexts, even though this is a very relevant activity in various clinical populations (e.g., patients with mild cognitive impairment or psychiatric or neurological disorders) in adults and children. The communication activities evaluated are very basic, such as making a phone call, sending a letter or filling in a form.

Finally, the classification of IADLs by the American Occupational Therapy Association is likely to be more adequate for adults than other populations and does not include other types of activities performed by children in an instrumental way in its taxonomy. Results showed a scarcity of instruments to assess children and adolescents. There are probably fewer tasks for evaluating multitasking in children because their development and the execution of IADLs progressively start at the age of 7 years in response to the demands of the environment [89]. Another important gap is the definition of IADLs for children from the age of 6 and for adolescents such as preparing the backpack for the next day, preparing clothes for the next day according to 
the schedule, preparing a snack, using means of communication (e.g. mobile phones, tablets) and money management.

\section{Types of tests according to the paradigm and technology}

We found several types of performance-based measures: (1) measures that focused on a single IADL (mainly naturalistic tasks); and (2) multitasking measures. Performance-based measures have been developed to assess functional capabilities to perform IADLs more objectively [90]. There is a great heterogeneity between the aspects or components of executive functions included in performance-based measures. In general, most tests include attentional control (i.e., action supervision and error detection), planning, sequencing, cognitive flexibility and goal setting as shown in Supplementary Table S2 and S3. In addition, some performance-based measures based on multitasking instruments include results on the effectiveness of prospective memory, especially related to time in adults (i.e., Sydney Test of Activities of Daily Living in Memory Disorders, Baycrest Multiple Errands Test, Test of Grocery Shopping Skills) and events in children (i.e.: DOEAT, Birthday Task). The study conducted by Vallejo et al. [80] confirmed previous findings that performance in multitasking in everyday life involves executive functions, prospective memory and retrospective memory. Thus, various processes work together in the performance of complex tasks. Among executive functions, planning is an essential component to accomplish novel tasks, as it is necessary to formulate an objective and establish the necessary actions to achieve it, with an appropriate sequence and taking into account personal strategies and specific rules. Prospective memory enables us to remember to conduct an activity planned for the future [91]. This is important because it implies that IADLs should not be examined as a set of cognitive processes only but rather considering how these processes work together as a whole, which may be more than the sum of its parts [80]. Conversely, in some tests performed in the real contexts of patients, such as the Assessment of Motor and Process Skills, School- Assessment of Motor and Process Skills or the Performance Assessment of Selfcare Skills, errors and attentional control are not evaluated nor can they be considered multitasking, since they do not require prospective memory and are not self-initiated by the subject. Baum et al. [92] reported that an advantage of naturalistic tasks is that they allow us to know what level of support is necessary for each patient and to be able to choose the best treatment. Although some limitations of naturalistic tasks based on the MET paradigm have been pointed out (e.g., their time-consuming nature, the transportation of patients to the setting of the evaluation, the consent of companies required in the case certain establishments such as shopping centers, the cooperation of staff and clients and the fact that there may be too many variables to control). While assessments based on naturalistic tasks can be understood as laboratory tasks and have high ecological validity, they require patients' abstract thinking to conceptualize the task; by contrast, instruments assessing IADLs in a real context tend to be produced depending on the learning history and the execution context [14]. Therefore, the former may not fully reflect the functioning of the real world [93]. Nevertheless, naturalistic tasks tend to motivate subjects more and lessen the anxiety that a traditional pen and paper evaluation can cause.

Regarding complex tasks such as financial management, the existing proposals only consider the payment of products that are to be bought. In relation to home establishment and management, they only cover tidying up a part of the home, such as a closet, and picking up the utensils needed to cook or prepare tea or another simple hot beverage. With regard to the preparation of menus, only the making of very simple recipes is considered, which in some cases involves only heating a pizza or spreading something on toast. In addition, safety procedures are evaluated in very few tasks; in the few cases in which they are, they are very basic, such as not making a mistake when picking up a knife. In summary, is important to note that some tasks are very simple (e.g., preparing breakfast) and there is a ceiling effect, which makes it impossible to identify people with mild cognitive impairment [68].

Furthermore, some of these assessments do not consider the resolution of a problem in an emergency or dangerous situation. Some of them, such as the Assessment of Motor and Process Skills, the Kettle Test, some MET-based assessments and the Test of Actual Reality are based on the test paradigm and do not make it possible to determine the functional level of participants when they require help. By contrast, the Executive Function Performance Test $[91,92]$ collects information on the type of help needed and how participants conduct their activity with the support they receive.

In naturalistic tasks there are a number of variables that can affect the performance of individuals and cannot be controlled (e.g., the amount of noise, people who spontaneously may or may not cooperate with the task, for example in a supermarket). Another limitation is that only a certain number of variables can be measured, since it is difficult for the observer to write everything down and it requires a lot of training and time and a high cost and involves poor control of several variables and lack of security [94,95]. Sometimes, if video recording is used it may affect the natural performance of the patient. In addition, in all these activities in the real world there is a great influence of the familiarity of the evaluated task, which affects the performance of executive functions. The scenarios evaluated using performancebased measures should be as complex as the real world and, at the same time, meaningful and of an everyday nature, with rules for the use of context and the execution of the activity. Therefore, there is a need for standardized tools that are accessible in a clinical setting and closely related to real-world activities, but at the same time place participants in new situations for them [14].

Virtual reality has been used to overcome some of these limitations. In fact, virtual reality is increasingly used in the evaluation of functional skills because of it has predictive value regarding functioning in daily life $[55,65,96-99]$. Tasks based on the MET paradigm that involve virtual reality are better at predicting the actual functioning of patients [100]. Virtual reality technology allows immersion in real situations, where the performance of the patient in IADLs can be observed. Virtual reality systems facilitate a three-dimensional presentation and the stimulation of dynamic environments, especially in evaluation scenarios that would be difficult to implement in real-world settings [72]. We found 32 references with virtual reality tasks (see Supplementary Table S1). Despite the importance of evaluating multitasking skills to predict the functioning of individuals in the real environment, their use is still infrequent, probably due to implementation difficulties in the laboratory [80].

Assessments involving computerized tests provide accurate measurements in milliseconds. Such tests have the following characteristics: they are more sensitive to cognitive impairment and are usually faster to administer; the presentation of items in some batteries can be adapted to the levels of performance of the patient to avoid floor effects; they guarantee standardization and examiner effects are reduced; scores are automatic, which means that results are available immediately and human scoring error is 
reduced; and they tend to have high portability [101]. According to other authors, the inclusion of real-world scenarios and virtual reality tasks in clinical studies can be a good means to demonstrate the impact of executive deficits on patients' lives [102,103], providing a sensitive measure of daily functioning [102,104]. Another advantage of this type of evaluation, particularly with children, is that it can assess them as if it were a game with a meaningful activity for them, decreasing their anxiety before the evaluation and the effects of feeling observed. In addition, such virtual reality tasks are similar to cognitive IADLs because they make it possible to easily include and design elements of the environment (e.g., familiar environment, more or fewer distractors or objects) through multitasking instruments [105]. A final advantage of using such assessments is that they can predict the level of personal autonomy in patients who are in an institutional environment and could be a first approximation to the real environment in patients with a mental disorder or drug abuse, for example. Based on the studies reviewed it can be stated that virtual environments and serious games for neurorehabilitation [105] and for the assessment of cognitive IADLs are increasingly being used in research to increase the ecological validity of assessments. However, results showed a very small number of virtual scenarios for the evaluation of executive functions in children and adolescents: only five instruments - two focused on kitchen tasks, one on office tasks, one on community mobility and one on attentional control in the classroom. Recent studies have started to include self-awareness as a parameter assessed with virtual reality [106]. In the future this could be of great interest for the assessment of IADLs. Virtual reality is even being considered to evaluate decision making regarding risk behaviors [107].

Some disadvantages of virtual reality tasks have been described: (1) they can cause dizziness (e.g., discomfort, nausea, vomiting, headache, fatigue) due to their inability to accurately simulate movements in the environment; (2) they involve costly technology, particularly if they are immersive; (3) they require regular maintenance; (4) their development requires multidisciplinary work involving computer engineers, neuropsychologists, occupational therapists and others; and (5) they have certain technical requirements such as lighting and broad spaces to be used. One of the pending tasks of virtual reality tests is to provide parallel versions of the task to avoid the learning effect in reassessments [35].

In conclusion, the main benefits of virtual reality for the evaluation of IADLs include affordability, safety, efficiency, applicability to a wide range of conditions and ease of data capture and qualification [21,34].

Many emerging technologies can be used for the evaluation of IADLs. A few examples are robots, depth cameras, event monitoring systems, body or environment sensors and serious games, among others, which make it possible to analyze movement and to predict and detect falls. In short, they make it possible to assess patients even when the therapist is absent, something known as Ecological Momentary Assessment. In an Ecological Momentary Assessment, a series of repeated measures are performed in various dimensions (e.g., cognitive, affective, physiological) while subjects perform IADLs without the need for a therapist to be present [108]. These new ecological paradigms provide a better understanding in the area of everyday multitasking and underline the importance of using virtual environments for exploring complex human cognition [80].

Finally, serious games have the potential to be used as multitasking assessment tools for cognition and performance in ADLs
[80] as they improve motivation [109] and have shown to have ecological validity [110] and diagnostic value [111].

\section{Tests according to the diagnosis}

From a clinical perspective, several authors have indicated the interest of evaluating IADLs through performance-based measures for the early detection of dysfunctions in IADLs. This has also been called 'preclinical disability'. This is especially true in older or chronically disabled persons [112], who may not show a decrease in the overall number of activities carried out but may exhibit changes in the frequency and quality of their performance. Therefore, the assessment of cognitive IADLs becomes even more interesting given the trend in the population, which is increasingly aging and has a higher prevalence of diseases leading to cognitive impairments (i.e., dementia, Parkinson's, severe mental illness, substance use disorders and neurodevelopmental disorders). Of these, it is worth highlighting attention deficit disorders and autism spectrum disorders, which have a high impact on executive functions and personal autonomy [113].

In this review we selected the tests and instruments available to assess cognitive IADLs. We observed that many studies were aimed at assessing the relationship, correlation and predictive power of certain cognitive processes on performance or level of functioning in daily life rather than at developing specific tests to assess cognitive instrumental activities of daily living. Of the various cognitive processes, memory and executive functions were those found to be most related to the performance of IADLs [114].

Assessments with ecological validity show the patterns of performance of several pathologies. For example, when participants with mild cognitive impairment performed IADLs, they made more substitution than omission mistakes when they were interrupted [82,114]. Such assessments provide information about what spontaneous strategies patients use, whether such strategies are useful, what type of information they learn with greater ease and what kind of support will benefit them the most in real life [115].

Results showed that most of the instruments found used performance-based measures, followed by behavior rating scales for caregivers; self-report methodologies were the least numerous instruments. This is consistent with the lack of awareness of the deficits and scarce insight into problems of patients with cognitive and/or mental impairment, which results in a decrease in the reliability and sensitivity of self-reports in these populations [113].

There is some controversy about whether or not the assessment of cognitive IADLs with virtual reality makes it possible to determine the strategies and aids that patients use to perform the activities. Some authors report that it is possible [116], although other authors argue that virtual reality does not fully replicate all the demands of daily life nor the aids or compensatory strategies that patients use [117]. Studies that use virtual tasks need to expand the sample size and diversity of those of cognitive and neuropsychiatric disorders. Kitchen-related tasks may be gender oriented, which is a limitation for their use and validity and sensitivity, among others. In relation to the question about whether instruments with simulated tasks correlate well with performance in tests based on real performance, we found the following: a study conducted with patients with serious mental illness [118] showed that tasks simulated in controlled conditions were a strong predictor of performance in real-world tasks. This study also found that verbal memory correlated positively with independence in the community. According to these authors, 
it is interesting to develop new systems for naturalistic evaluation, since most assessment tools available to date do not fully explain performance in the real world [118]. It is necessary to clinically validate all technologies and determine whether they have predictive validity over functional performance. Yet, the use of technology in the evaluation of IADLs is not without disadvantages, such as energy consumption and the limited use of wireless devices. In some cases, when it is necessary to record patient's performance and use environmental or personal sensors, this may threaten the privacy of patients.

So far, the use of various assessment tasks has been done mainly experimentally and few of the tests available have been the subject of studies with clinical validity reporting effect sizes [115]. One of the challenges of such evaluation systems is expanding them to make them appropriate for the entire population and available to clinicians in order to facilitate and improve the evaluation of IADLs. It is also necessary to conduct studies on the acceptability of technology both by therapists and patients and it would be good to make these IADL evaluation tools affordable for the entire population.

Thanks to the multidisciplinary work of computer engineers, occupational therapists and neuropsychologists, more solidly constructed tests will be available in the future [119]. Considering the knowledge obtained by the three disciplines can improve the quality of care and consequently the quality of life of the population.

\section{Limitations of the study and implications for future research}

This systematic review has certain limitations. First, the results shown were limited to the years on which the systematic review focused, and there may be other previous tests that were not found with the inclusion criteria. Second, as noted by other authors, the conclusions about convergent validity in daily life were limited because there is no gold standard measurement of cognitive IADLs against which these measures can be compared to [37]. Some authors compared the test with traditional measures of executive functions, such as the Stroop task, Wisconsin Card Sort Test or Continuous Performance Test [120], while others simply labeled their measure as ecological given the way they had designed and developed it.

\section{Disclosure statement}

The authors declare that no conflict of interest exists in association with the current review.

\section{Funding}

This research did no receive any specific grants from funding agencies in the public, commercial, or not-for-profit sectors.

\section{References}

[1] IMSERSO. Atención a las personas con dependencia en España. Libro Blanco. Madrid: Ministerio de Trabajo y Asuntos Sociales; 2004.

[2] Chakra A. A life skills approach to adolescent development. Int J Home Sci. 2016;2(1):234-238.

[3] Edwards DF, Wolf TJ, Marks T, et al. Reliability and validity of a functional cognition screening tool to identify the need for occupational therapy. Am J Occup Ther. 2019;73(2):7302205050p1-7302205050p10. DOI:10.5014/ ajot.2019.028753

[4] Poncet F, Swaine B, Dutil E, et al. How do assessments of activities of daily living address executive functions: a scoping review. Neuropsychol Rehabil. 2017;27(5): 618-666.

[5] American Occupational Therapy Association (AOTA). Occupational therapy practice. Framework: domain \& process (3rd ed.). Am J Occup Ther. 2014;68(S1):S1-S48.

[6] Toglia J, Askin G, Gerber LM, et al. Association between 2 measures of cognitive instrumental activities of daily living and their relation to the montreal cognitive assessment in persons with stroke. Arch Phys Med Rehabil. 2017;98(11):2280-2287.

[7] Gulde P, Schmidle S, Aumüller A, et al. The effects of speed of execution on upper-limb kinematics in activities of daily living with respect to age. Exp Brain Res. 2019; 237(6):1383-1395.

[8] Gamaldo AA, Allaire JC. Daily fluctuations in everyday cognition: is it meaningful? J Aging Health. 2016;28(5): 834-849.

[9] Allaire JC, Gamaldo A, Ayotte BJ, et al. Mild cognitive impairment and objective instrumental everyday functioning: the everyday cognition battery memory test. J Am Geriatr Soc. 2009;57(1):120-125.

[10] Bielak A. Different perspectives on measuring lifestyle engagement: a comparison of activity measures and their relation with cognitive performance in older adults. Neuropsychol Dev Cogn B Aging Neuropsychol Cogn. 2017;24(4):435-452.

[11] Wesson J, Clemson L, Brodaty $\mathrm{H}$, et al. Estimating functional cognition in older adults using observational assessments of task performance in complex everyday activities: a systematic review and evaluation of measurement properties. Neurosci Biobehav Rev. 2016;68:335-360.

[12] Burgess PW, Veitch E, de Lacy Costello A, et al. The cognitive and neuroanatomical correlates of multitasking. Neuropsychologia. 2000;38(6):848-863.

[13] Logie $\mathrm{RH}$, Trawley S, Law A. Multitasking: multiple, domain-specific cognitive functions in a virtual environment. Mem Cogn. 2011;39(8):1561-1574.

[14] Laloyaux J, Van der Linden $\mathrm{M}$, Nuechterlein $\mathrm{KH}$, et al. A direct examination of the cognitive underpinnings of multitasking abilities: a first study examining schizophrenia. Psychiatry Res. 2018;268:288-296.

[15] Boyle PA, Cohen RA, Paul R, et al. Cognitive and motor impairments predict functional declines in patients with vascular dementia. Int J Geriat Psychiatry. 2002;17(2): 164-169.

[16] Mlinac ME, Feng MC. Assessment of activities of daily living, self-care, and independence. Arch Clin Neuropsychol. 2016;31(6):506-516.

[17] Allaire JC, Willis SL. Competence in everyday activities as a predictor of cognitive risk and mortality. Neuropsychol Dev Cogn B Aging Neuropsychol Cogn. 2006;13(2): 207-224.

[18] Nott MT, Chapparo C, Heard R. Effective occupational therapy intervention with adults demonstrating agitation during post-traumatic amnesia. Brain Inj. 2008;22(9): 669-683.

[19] Adamit T, Maeir A, Ben Assayag E, et al. Impact of firstever mild stroke on participation at 3 and 6 month post- 
event: the TABASCO study. Disabil Rehabil. 2015;37(8): 667-673.

[20] Wolf TJ, Dahl A, Auen C, et al. The reliability and validity of the complex task performance assessment: a performance-based assessment of executive function. Neuropsychol Rehabil. 2017;27(5):707-721.

[21] Júlio $F$, Ribeiro MJ, Patrício $M$, et al. A novel ecological approach reveals early executive function impairments in huntington's disease. Front Psychol. 2019;10:585.

[22] Shea-Shumsky NB, Schoeneberger S, Grigsby J. Executive functioning as a predictor of stroke rehabilitation outcomes. Clin Neuropsychol. 2019;33(5):854-872.

[23] Mcalister C, Schmitter-Edgecombe $M$, Lamb R. Examination of variables that may affect the relationship between cognition and functional status in individuals with mild cognitive impairment: a meta-analysis. Arch Clin Neuropsychol. 2016;31(2):123-147.

[24] Freilich BM, Hyer LA. Relation of the repeatable battery for assessment of neuropsychological status to measures of daily functioning in dementia. Psychol Rep. 2007; 101(1):119-129.

[25] Holmqvist $K L$, Holmefur $M$, Arvidsson P. Test-retest reliability of the Swedish version of the weekly calendar planning activity - a performance-based test of executive functioning. Disabil Rehabil. 2019. DOI:10.1080/09638288. 2019.1568590

[26] Burgess PW, Alderman N, Forbes $C$, et al. The case for the development and use of "ecologically valid" measures of executive function in experimental and clinical neuropsychology. J Int Neuropsychol Soc. 2006;12(2):194-209.

[27] Burgess PW, Alderman N, Volle E, et al. Mesulam's frontal lobe mystery re-examined. Restor Neurol Neurosci. 2009; 27(5):493-506.

[28] Beyle A, Glonnegger H, Cerff B, et al. Liepelt-Scarfone I. The Multiple Object Test as a performance-based tool to assess the decline of ADL function in Parkinson's disease. PLoS One. 2018;13(8):e0200990.

[29] Burgess PW, Alderman N, Wilson BA, et al. Validity of the battery: Relationship between performance on the BADS and ratings of executive problems $\mathrm{In}$ : Wilson $\mathrm{BA}$, editor. BADS: Behavioural assessment of the dysexecutive syndrome manual. Bury St Edmunds (UK): Thames Valley Test Company; 1996. p. 18-19.

[30] Chan RC, Shum D, Toulopoulou T, et al. Assessment of executive functions: review of instruments and identification of critical issues. Arch Clin Neuropsychol. 2008;23(2): 201-216.

[31] Parsons TD. Virtual reality for enhanced ecological validity and experimental control in the clinical. Front Hum Neurosci. 2015;9:660.

[32] Ylvisaker M, Giola G. Comprehensive cognitive assessment In: Ylvisaker $M$, editor. Traumatic brain injury rehabilitation: children and adolescents. Boston: ButterworthHeinemann; 1998. p. 159-180.

[33] Brunswick E. Representative design and probabilistic theory in a functional psychology. Psychol Rev. 1955;62(3): 193-217.

[34] Parsons TD, Carlew AR, Magtoto J, et al. The potential of function-led virtual environments for ecologically valid measures of executive function in experimental and clinical neuropsychology. Neuropsychol Rehabil. 2017;27(5): 777-807.
[35] Martínez-Pernía D, Núñez-Huasaf J, Del Blanco Á, et al. Using game authoring platforms to develop screen-based simulated functional assessments in persons with executive dysfunction following traumatic brain injury. J Biomed Inform. 2017;74:71-84.

[36] Parsons TD. Neuropsychological Assessment using Virtual Environments: Enhanced Assessment Technology for Improved Ecological Validity In: Brahnam S, editor. Advanced computational intelligence paradigms in healthcare: virtual reality in psychotherapy, rehabilitation and assessment. Germany: Springer-Verlag; 2011. p. 271-289.

[37] Chevignard MP, Soo C, Galvin J, et al. Ecological assessment of cognitive functions in children with acquired brain injury: a systematic review. Brain Inj. 2012;26(9): 1033-1057.

[38] Teng E, Becker BW, Woo E, et al. Utility of the functional activities questionnaire for distinguishing mild cognitive impairment from very mild Alzheimer disease. Alzheimer Dis Assoc Disord. 2010;24(4):348-353.

[39] Rosetti MF, Ulloa RE, Vargas-Vargas IL, et al. Evaluation of children with ADHD on the Ball-Search Field Task. Sci Rep. 2016;6:19664

[40] Rendell PG, Mazur M, Henry JD. Prospective memory impairment in former users of methamphetamine. Psychopharmacology (Berl). 2009;203(3):609-616.

[41] Rose NS, Rendell PG, Hering A, et al. Cognitive and neural plasticity in older adults' prospective memory following training with the Virtual Week computer game. Front Hum Neurosci. 2015;9:592.

[42] Brown J, Hux K. Ecologically valid assessment of prospective memory for task planning and execution by adults with acquired brain injury. Am J Speech Lang Pathol. 2017;26(3):819-831.

[43] Parsons TD, McMahan T. An initial validation of the Virtual Environment Grocery Store. J Neurosci Methods. 2017;291: 13-19.

[44] Hale J, Payne ME, Taylor KM, et al. The virtual maze: a behavioural tool for measuring trust. Q J Exp Psychol (Hove). 2018;71(4):989-1008.

[45] Roll EE, Giovannetti T, Libon DJ, et al. Everyday task knowledge and everyday function in dementia. J Neuropsychol. 2017; 13(1):96-120.

[46] Allen CK, Austin SL, Earhart CA, et al. Manual for the Allen Cognitive Level Screen-5(ACL-5) and Large Allen Cognitive Level Screen (LACLS-5). Camarillo (CA): ACLS and LACLS; 2007.

[47] Parsons TD, Barnett M. Virtual Apartment-Based Stroop for assessing distractor inhibition in healthy aging. Appl Neuropsychol Adult. 2019;26(2):144-154.

[48] Patil I, Cogoni C, Zangrando N, et al. Affective basis of judgment-behavior discrepancy in virtual experiences of moral dilemmas. Soc Neurosci. 2014;9(1):94-107.

[49] Cook LG, Hanten G, Orsten KD, et al. Effects of moderate to severe traumatic brain injury on anticipating consequences of actions in adolescents: a preliminary study. J Int Neuropsychol Soc. 2013;19(5):508-517.

[50] Elkind JS, Rubin E, Rosenthal $S$, et al. A simulated reality scenario compared with the computerized Wisconsin card sorting test: an analysis of preliminary results. Cyberpsychol Behav. 2001;4(4):489-496.

[51] Mühlberger A, Jekel K, Probst $T$, et al. The influence of methylphenidate on hyperactivity and attention deficits in 
children with ADHD: a virtual classroom test. J Atten Disord. 2016. DOI:10.1177/1087054716647480

[52] Nolin P, Stipanicic A, Henry M, et al. ClinicaVR: classroomCPT: a virtual reality tool for assessing attention and inhibition in children and adolescents. Comput Hum Behav. 2016;59:327.

[53] Kirshner S, Weiss PL, Tirosh E. Meal-maker: a virtual meal preparation environment for children with cerebral palsy. Eur J Spec Needs Educ. 2011;26(3):323-336.

[54] Gilboa Y, Rosenblum S, Fattal-Valevski A, et al. Using a virtual classroom environment to describe the attention deficits profile of children with neurofibromatosis type 1. Res Dev Disabil. 2011;32(6):2608-2613.

[55] Renison B, Ponsford J, Testa R, et al. The ecological and construct validity of a newly developed measure of executive function: the Virtual Library Task. J Int Neuropsychol Soc. 2012;18(03):440-450.

[56] Jovanovski D, Zakzanis K, Campbell Z, et al. Development of a novel, ecologically oriented virtual reality measure of executive function: the Multitasking in the City Test. Appl Neuropsychol Adult. 2012;19(3):171-182.

[57] Faria AL, Andrade A, Soares L, I Badia SB. Benefits of virtual reality based cognitive rehabilitation through simulated activities of daily living: a randomized controlled trial with stroke patients. J Neuroeng Rehab. 2016; 13(1):96.

[58] Weniger G, Ruhleder M, Lange $C$, et al. Egocentric and allocentric memory as assessed by virtual reality in individuals with amnestic mild cognitive impairment. Neuropsychologia. 2011;49(3):518-527.

[59] Nir-Hadad SY, Weiss PL, Waizman A, et al. A virtual shopping task for the assessment of executive functions: validity for people with stroke. Neuropsychol Rehabil. 2017; 27(5):808-833.

[60] Saebo. Real-life simulating. Benefits of virtual reality for stroke rehabilitation. 2017 [cited 2017 Jul 11]. Available from: https://www.saebo.com/benefits-virtual-realitystroke-rehabilitation.

[61] Erez N, Weiss PL, Kizony R, et al. Comparing performance within a virtual supermarket of children with traumatic brain injury to typically developing children: a pilot study. OTJR (Thorofare N J). 2013;33(4):218-227.

[62] Rand D, Katz N, Weiss PL. Evaluation of virtual shopping in the VMall: comparison of post-stroke participants to healthy control groups. Disabil Rehabil. 2007;29(22): 1710-1719.

[63] Rand D, Basha-Abu Rukan S, Weiss PL, et al. Validation of the Virtual MET as an assessment tool for executive functions. Neuropsychol Rehabil. 2009;19(4):583-602.

[64] Allain P, Foloppe DA, Besnard J, et al. Detecting everyday action deficits in Alzheimer's disease using a nonimmersive virtual reality kitchen. J Int Neuropsychol Soc. 2014; 20(5):468-477.

[65] Besnard J, Richard P, Banville F, et al. Virtual reality and neuropsychological assessment: the reliability of a virtual kitchen to assess daily-life activities in victims of traumatic brain injury. Appl Neuropsychol Adult. 2016;23(3):223-235.

[66] Josman N, Somer E, Reisberg A, et al. BusWorld: designing a virtual environment for post-traumatic stress disorder in Israel: a protocol. Cyberpsychol Behav. 2006;9(2):241-244.

[67] Jansari AS, Devlin A, Agnew R, et al. Ecological assessment of executive functions: a new virtual reality paradigm. Brain Impairment. 2014;15(2):71-87.
[68] Gamito P, Oliveira J, Brito R, et al. Evaluation of cognitive functions through the systemic lisbon battery: normative data. Methods Inf Med. 2016;55(1):93-97.

[69] Oliveira CR, Lopes Filho BJ, Sugarman MA, et al. Development and feasibility of a virtual reality task for the cognitive assessment of older adults: the ECO-VR. Span J Psychol. 2016;19:E95.

[70] Wiemeyer J, Kliem A. Serious games in prevention and rehabilitation-a new panacea for elderly people? 9. Eur Rev Aging Phys Act. 2011;9:41-50.

[71] Bottiroli S, Tassorelli C, Lamonica $M$, et al. Smart aging platform for evaluating cognitive functions in aging: a comparison with the MoCA in a normal population. Front Aging Neurosci. 2017;9:379.

[72] Cook DJ, Schmitter-Edgecombe $M$, Jonsson $L$, et al. Technology-enabled assessment of functional health. IEEE Rev Biomed Eng. 2019;12:319-332.

[73] Rycroft SS, Giovannetti T, Shipley TF, et al. Windows to functional decline: naturalistic eye movements in older and younger adults. Psychol Aging. 2018;33(8):1215-1222.

[74] Robertson K, Schmitter-Edgecombe M. Naturalistic tasks performed in realistic environments: a review with implications for neuropsychological assessment. Clin Neuropsychol. 2017;31(1):16-42.

[75] Shallice T, Burgess PW. Deficits in strategy application following frontal lobe damage in man. Brain. 1991;114(2): 727-741.

[76] McFadyen BJ, Gagné M, Cossette I, et al. Using dual task walking as an aid to assess executive dysfunction ecologically in neurological populations: a narrative review. Neuropsychol Rehabil. 2017;27(5):722-743.

[77] Faith LA, Rempfer MV. Comparison of performance-based assessment and real world skill in people with serious mental illness: ecological validity of the Test of Grocery Shopping Skills. Psychiatry Res. 2018;266:11-17.

[78] Aubin G, Béliveau MF, Klinger E. An exploration of the ecological validity of the Virtual Action PlanningSupermarket (VAP-S) with people with schizophrenia. Neuropsychol Rehabil. 2018;28(5):689-708.

[79] Noll KR, Bradshaw ME, Weinberg JS, et al. Neurocognitive functioning is associated with functional independence in newly diagnosed patients with temporal lobe glioma. Neurooncol Pract. 2018;5(3):184-193.

[80] Vallejo V, Wyss P, Rampa L, et al. Evaluation of a novel Serious Game based assessment tool for patients with Alzheimer's disease. PLoS One. 2017;12(5):e0175999.

[81] Kizony R, Demayo-Dayan T, Sinoff G, et al. Validation of the executive function route-finding task (EFRT) in people with mild cognitive impairment. OTJR (Thorofare $\mathrm{N} \mathrm{J}$ ). 2011;31(1):S47-S52.

[82] Weakley A, Schmitter-Edgecombe M. Naturalistic assessment of task interruption in individuals with mild cognitive impairment. Neuropsychology. 2019;33(1):1-12.

[83] Farias ST, Mungas D, Reed BR, et al. The measurement of everyday cognition (ECog): scale development and psychometric properties. Neuropsychology. 2008;22(4): 531-544.

[84] Dassel KB, Schmitt FA. The impact of caregiver executive skills on reports of patient functioning. Gerontologist. 2008;48(6):781-792.

[85] Dickerson AE, Meuel DB, Ridenour CD, et al. Assessment tools predicting fitness to drive in older adults: a systematic review. Am J Occup Ther. 2014;68(6):670-680. 
[86] Ratzon NZ, Lunievsky EK, Ashkenasi A, et al. Simulated driving skills evaluation of teenagers with attention deficit hyperactivity disorder before driving lessons. Am J Occup Ther. 2017;71(3):7103220010p1-7103220010p8. DOI:10. 5014/ajot.2017.020164

[87] Bédard MB, Parkkari $M$, Weaver $B$, et al. Assessment of driving performance using a simulator protocol: validity and reproducibility. Am J Occup Ther. 2010;64(2):336-340.

[88] Yuval-Greenberg S, Keren A, Hilo R, et al. Gaze control during simulator driving in adolescents with and without attention deficit hyperactivity disorder. Am J Occup Ther. 2019;73(3):7303345030p1-7303345030p8. DOI:10.5014/ajot. 2019.031500

[89] Moruno P, Romero D. Actividades de la Vida Diaria. Barcelona: Elsevier; 2006.

[90] Schmitter-Edgecombe M, Parsey CM. Cognitive correlates of functional abilities in individuals with mild cognitive impairment: comparison of questionnaire, direct observation, and performance-based measures. Clin Neuropsychol. 2014;28(5):726-746.

[91] Potvin MJ, Rouleau I, Audy J, et al. Ecological prospective memory assessment in patients with traumatic brain injury. Brain Inj. 2011;25(2):192-205.

[92] Baum CM, Connor LT, Morrison T, et al. Reliability, validity, and clinical utility of the Executive Function Performance Test: a measure of executive function in a sample of people with stroke. Am J Occup Ther. 2008;62(4):446-455.

[93] Zanetti O, Geroldi C, Frisoni GB, et al. Contrasting results between caregiver's report and direct assessment of activities of daily living in patients affected by mild and very mild dementia: the contribution of the caregiver's personal characteristics. J Am Geriatr Soc. 1999;47(2): 196-202.

[94] Schwartz Y, Averbuch S, Katz N, et al. Validity of the Functional Loewenstein Occupational Therapy Cognitive Assessment (FLOTCA). Am J Occup Ther. 2016;70(1): 7001290010p1-7001290010p7.

[95] Serino S, Baglio F, Rossetto F, et al. Picture Interpretation Test (PIT) $360^{\circ}$ : an innovative measure of executive functions. Sci Rep. 2017;7(1):16000.

[96] Christiansen C, Abreu B, Ottenbacher K, et al. Task performance in virtual environments used for cognitive rehabilitation after traumatic brain injury. Arch Phys Med Rehabil. 1998;79(8):888-892.

[97] Lee JH, Ku J, Cho W, et al. A virtual reality system for the assessment and rehabilitation of the activities of daily living. Cyberpsychol Behav. 2003;6(4):383-388.

[98] Zhang L, Abreu BC, Masel B, et al. Virtual reality in the assessment of selected cognitive function after brain injury. Am J Phys Med Rehabil. 2001;80(8):597-604.

[99] Zhang L, Abreu BC, Seale GS, et al. A virtual reality environment for evaluation of a daily living skill in brain injury rehabilitation: reliability and validity. Arch Phys Med Rehabil. 2003;84(8):1118-1124.

[100] Alderman N, Burgess PW, Knight C, et al. Ecological validity of a simplified version of the multiple errands shopping test. J Int Neuropsychol Soc. 2003;9(1):31-44.

[101] Collerton J, Collerton D, Arai Y, et al. A comparison of computerized and pencil-and-paper tasks in assessing cognitive function in community-dwelling older people in the Newcastle 85+ Pilot Study. J Am Geriatr Soc. 2007; 55(10):1630-1635.
[102] Frisch S, Förstl S, Legler A, et al. The interleaving of actions in everyday life multitasking demands. J Neuropsychol. 2012;6(2):257-269.

[103] Albani G, Raspelli S, Carelli L, et al. Executive functions in a virtual world: a study in Parkinson's disease. Stud Health Technol Inform. 2010;154:92-96.

[104] Poliakoff E, Smith-Spark JH. Everyday cognitive failures and memory problems in Parkinson's patients without dementia. Brain Cogn. 2008;67(3):340-350.

[105] Valladares-Rodríguez S, Pérez-Rodríguez R, Anido-Rifón L, et al. Trends on the application of serious games to neuropsychological evaluation: a scoping review. J Biomed Inform. 2016;64:296-319.

[106] Muratore $M$, Tuena $C$, Pedroli E, et al. Virtual reality as a possible tool for the assessment of self-awareness. Front Behav Neurosci. 2019;13:62

[107] De-Juan-Ripoll C, Soler-Dominguez J, Guixeres J, et al. Virtual reality as a new approach for risk taking assessment. Front Psychol. 2018;9:2532.

[108] Kane RL, Parsons TD. Technological developments in assessment. In: Goldstein G, Allen DN, DeLuca J, editors. Handbook of psychological assessment. 4th ed. Psychological Assessment. London: Academic Press; 2019.

[109] Riva G. Virtual reality in psychotherapy: review. Cyberpsychol Behav. 2005;8(3):220-230. discussion 31-40.

[110] Tarnanas I, Schlee W, Tsolaki M, et al. Ecological validity of virtual reality daily living activities screening for early dementia: longitudinal study. JMIR Serious Games. 2013; 1(1):e1.

[111] Tarnanas I, Tsolaki M, Nef T, et al. Can a novel computerized cognitive screening test provide additional information for early detection of Alzheimer's disease? Alzheimers Dement. 2014;10(6):790-798.

[112] Terhorst L, Holm MB, Toto PE, et al. Performance-based impairment measures as predictors of early-stage activity limitations in community-dwelling older adults. J Aging Health. 2017;29(5):880-892.

[113] Stucki RA, Urwyler P, Rampa L, et al. A web-based nonintrusive ambient system to measure and classify activities of daily living. J Med Internet Res. 2014;16(7):e175.

[114] Overdorp EJ, Kessels RP, Claassen JA, et al. The combined effect of neuropsychological and neuropathological deficits on instrumental activities of daily living in older adults: a systematic review. Neuropsychol Rev. 2016;26(1): 92-106.

[115] Lewis MW, Babbage DR, Leathem JM. Systematic behavioural observation of executive performance after brain injury. Brain Inj. 2017;31(5):639-648.

[116] Cipresso P, Albani G, Serino S, et al. Virtual multiple errands test (VMET): a virtual reality-based tool to detect early executive functions deficit in Parkinson's disease. Front Behav Neurosci. 2014;8:405.

[117] Pietrzak E, Pullman S, McGuire A. Using virtual reality and videogames for traumatic brain injury rehabilitation: a structured literature review. Games Health J. 2014;3(4): 202-214.

[118] Rempfer MV, Fowler CA. Relationships among functional capacity, cognition, and naturalistic skill performance in people with serious mental illness. Psychiatry Res. 2018; 270:453-458.

[119] Juvina I, Taatgen NA. A repetition-suppression account of between-trial effects in a modified Stroop paradigm. Acta Psychol (Amst). 2009;131(1):72-84. 
[120] Baron IS. Neuropsychological evaluation of the child. Oxford: Oxford University Press; 2004.

[121] De Vriendt P, Gorus E, Cornelis E, et al. The process of decline in advanced activities of daily living: a qualitative explorative study in mild cognitive impairment. Int Psychogeriatr. 2012;24(6):974-986.

[122] Katz N. Routine Task Inventory - Expanded (RTI-E) manual, prepared and elaborated on the basis of Allen, C.K. 1989.

[123] Fisher AG, Bryze K, Atchison BT. Naturalistic assessment of functional performance in school settings: reliability and validity of the School AMPS scales. J Outcome Meas. 2000;4(1):491-512.

[124] Chisholm D, Toto P, Raina K, et al. Evaluating capacity to live independently and safely in the community: performance assessment of self-care skills. Br J Occup Ther. 2014; 77(2):59-63.

[125] Pickens S, Naik AD, Burnett J, et al. The utility of the Kohlman Evaluation of Living Skills test is associated with substantiated cases of elder self-neglect. J Am Acad Nurse Pract. 2007;19(3):137-142.

[126] Baum CM, Morrison T, Hahn M, et al. Test manual: executive function performance test. St. Louis (MO): Washington University; 2003.

[127] Reppermund S, Birch RC, Crawford JD, et al. Performancebased assessment of instrumental activities of daily living: validation of the Sydney test of activities of daily living in memory disorders (STAM). J Am Med Dir Assoc. 2017; 18(2):117-122.

[128] Knight C, Alderman N, Burgess PW. Development of a simplified version of the multiple errands test for use in hospital settings. Neuropsychol Rehabil. 2002;12(3): 231-235.

[129] Dawson DR, Anderson ND, Burgess $P$, et al. Further development of the multiple errands test: standardized scoring, reliability, and ecological validity for the Baycrest version. Arch Phys Med Rehabil. 2009;90(11):S41-S51.

[130] Goverover Y, DeLuca J. Actual reality: using the internet to assess everyday functioning after traumatic brain injury. Brain Inj. 2015;29(6):715-721.

[131] Patterson TL, Goldman S, McKibbin CL, et al. UCSD performance-based skills assessment: development of a new measure of everyday functioning for severely mentally ill adults. Schizophr Bull. 2001;27(2):235-245.

[132] Mausbach BT, Harvey PD, Goldman SR, et al. Development of a brief scale of everyday functioning in persons with serious mental illness. Schizophr Bull. 2006; 33(6):1364-1372.

[133] Manly T, Hawkins K, Evans J, et al. Rehabilitation of executive function: facilitation of effective goal management on complex tasks using periodic auditory alerts. Neuropsychologia. 2002;40(3):271-281.

[134] Diehl $M$, Marsiske $M$, Horgas $A L$, et al. The revised observed tasks of daily living: a performance-based assessment of everyday problem solving in older adults. J Appl Gerontol. 2005;24(3):211-230.

[135] Book S, Luttenberger K, Stemmler M, et al. The Erlangen test of activities of daily living in persons with mild dementia or mild cognitive impairment (ETAM) - an extended validation. BMC Psychiatry. 2018;18(1):308

[136] Coster WJ, Haley SM, Ludlow LH, et al. Development of an applied cognition scale to measure rehabilitation outcomes. Arch Phys Med Rehabil. 2004;85(12):2030-2035.
[137] Sánchez-Pérez A, López-Roig S, Pampliega Pérez A, et al. Translation and adaptation of the Disability Assessment for Dementia scale in the Spanish population. Med Clin (Barc). 2017;149(6):248-252.

[138] Rosenblum S, Josman N, Toglia J. Development of the Daily Living Questionnaire (DLQ): a factor analysis study. OJOT. 2017;5(4):1-17.

[139] Rossier P, Wade DT, Murphy M. An initial investigation of the reliability of the Rivermead Extended $A D L$ index in patients presenting with neurological impairment. J Rehabil Med. 2001;33(2):61-70.

[140] Schmitter-Edgecombe M, Parsey CM. Assessment of functional change and cognitive correlates in the progression from healthy cognitive aging to dementia. Neuropsychology. 2014;28(6):881-893.

[141] Owsley C, Sloane M, McGwin G, et al. Timed instrumental activities of daily living tasks: relationship to cognitive function and everyday performance assessments in older adults. Gerontology. 2002;48(4):254-265.

[142] Canty AL, Fleming J, Patterson F, et al. Evaluation of a virtual reality prospective memory task for use with individuals with severe traumatic brain injury. Neuropsychol Rehabil. 2014;24(2):238-265.

[143] Rosetti M, Gomez-Tello M, Figeroa G, et al. A video game for the neuropsychological screening of children. Entertain Comput. 2017;20:1-9. DOI:10.1016/j.entcom. 2017.02.002

[144] Rempfer MV, Hamera EK, Brown CE, et al. The relations between cognition and the independent living skill of shopping in people with schizophrenia. Psychiatry Res. 2003;117(2):103-112.

[145] Sanders C, Low C, Schmitter-Edgecombe M. Assessment of planning abilities in individuals with mild cognitive impairment using an open-ended problem-solving task. J Clin Exp Neuropsychol. 2014;36(10):1084-1097.

[146] Valls-Serrano C, Verdejo-García A, Noël $X$, et al. Development of a contextualized version of the multiple errands test for people with substance dependence. J Int Neuropsychol Soc. 2018;24(4):347-359.

[147] Schmitter-Edgecombe M, McAlister C, Weakley A Naturalistic assessment of everyday functioning in individuals with mild cognitive impairment: the day-out task. Neuropsychology. 2012;26(5):631-641.

[148] Labra-Pérez J, Menor J. Development and validation of a performance-based test to assess instrumental activites of daily living in Spanish older adults. Eur J Psychol Assess. 2018;34(6):386-398.

[149] Dutil E, Forget A, Vanier $M$, et al. Development of the ADL profile. Occup Ther Health Care. 1990;7(1):7-22.

[150] Rabin LA, Paolillo E, Barr WB. Stability in test-usage practices of clinical neuropsychologists in the United States and Canada over a 10-year period: a follow-up survey of INS and NAN members. Arch Clin Neuropsychol. 2016;31(3): 206-230.

[151] Emmert NA, Schwarz LR, Vander Wal JS, et al. Neuropsychological predictors of health and safety abilities in dementia. Appl Neuropsychol Adult. 2019. DOI: 10.1080/23279095.2019.1599893

[152] Rodríguez-Bailón M, Montoro-Membila N, Garcia-Morán T, et al. Preliminary cognitive scale of basic and instrumental activities of daily living for dementia and mild cognitive impairment. J Clin Exp Neuropsychol. 2015;37(4):339-353. 
[153] Leyva A, Balachandran A, Britton JC, et al. The development and examination of a new walking executive function test for people over 50 years of age. Physiol Behav. 2017; 171:100-109.

[154] Josman N, Kizony R, Hof E, et al. Using the virtual action planning-supermarket for evaluating executive functions in people with stroke. J Stroke Cerebrovasc Dis. 2014; 23(5):879-887.

[155] Cipresso P, Serino S, Gaggioli A, et al. Contactless biobehavioral technologies for virtual reality. Stud Health Technol Inform. 2013;191:149-153.

[156] Pedroli E, Cipresso P, Serino S, et al. Virtual Multiple Errands Test: reliability, usability and possible applications. Stud Health Technol Inform. 2013;191:38-42.

[157] La Paglia F, La Cascia C, Rizzo R, et al. Cognitive assessment of OCD patients: NeuroVR vs neuropsychological test. Stud Health Technol Inform. 2014;199:40-44.

[158] Sauzéon H, N'Kaoua B, Arvind Pala P, et al. Age and active navigation effects on episodic memory: a virtual reality study. Br J Psychol. 2016;107(1):72-94.

[159] Werner P, Rabinowitz S, Klinger $E$, et al. Use of the virtual action planning supermarket for the diagnosis of mild cognitive impairment: a preliminary study. Dement Geriatr Cogn Disord. 2009;27(4):301-309.

[160] Jovanovski D, Zakzanis K, Ruttan L, et al. Ecologically valid assessment of executive dysfunction using a novel virtual reality task in patients with acquired brain injury. Appl Neuropsychol Adult. 2012;19(3):207-220.

[161] Law AS, Trawley SL, Brown LA, et al. The impact of working memory load on task execution and online plan adjustment during multitasking in a virtual environment. Q J Exp Psychol (Hove). 2013;66(6):1241-1258.

[162] Avis KT, Gamble KL, Schwebel DC. Does excessive daytime sleepiness affect children's pedestrian safety? Sleep. 2014; 37(2):283-287.

[163] Clancy TA, Rucklidge JJ, Owen D. Road-crossing safety in virtual reality: a comparison of adolescents with and without ADHD. J Clin Child Adolesc Psychol. 2006;35(2): 203-215.

[164] Buxbaum LJ, Dawson AM, Linsley D. Reliability and validity of the Virtual Reality Lateralized Attention Test in assessing hemispatial neglect in right-hemisphere stroke. Neuropsychology. 2012;26(4):430-441.

[165] Parsons TD, Rizzo AA. Initial validation of a virtual environment for assessment of memory functioning: virtual reality cognitive performance assessment test. Cyberpsychol Behav. 2008;11(1):17-25.

[166] Steverson T, Adlam AR, Langdon PE. Development and validation of a modified multiple errands test for adults with intellectual disabilities. J Appl Res Intellect Disabil. 2017;30(2):255-268.

[167] Hamera E, Brown CE. Developing a context-based performance measure for persons with schizophrenia: the test of grocery shopping skills. Am J Occup Ther. 2000; 54(1):20-25.

[168] Marshall GA, Aghjayan SL, Dekhtyar M, et al. Measuring instrumental activities of daily living in non-demented elderly: a comparison of the new performance-based Harvard Automated Phone Task with other functional assessments. Alzheimers Res Ther. 2019;11(1):4.

[169] Allaire JC, Marsiske M. Everyday cognition: age and intellectual ability correlates. Psychol Aging. 1999;14(4): 627-644
[170] Climent-Martínez G, Luna-Lario P, Bombín-González I, et al. [Neuropsychological evaluation of the executive functions by means of virtual reality]. Rev Neurol. 2014; 58(10):465-475.

[171] Toet A, van Schaik MG. Visual attention for a desktop virtual environment with ambient scent. Front Psychol. 2013; 4:883.

[172] Jacoby $M$, Averbuch $S$, Sacher $Y$, et al. Effectiveness of executive functions training within a virtual supermarket for adults with traumatic brain injury: a pilot study. IEEE Trans Neural Syst Rehabil Eng. 2013;21(2):182-190.

[173] Zartman AL, Hilsabeck RC, Guarnaccia CA, et al. The Pillbox Test: an ecological measure of executive functioning and estimate of medication management abilities. Arch Clin Neuropsychol. 2013;28(4):307-319.

[174] Reisberg B, Finkel S, Overall J, et al. The Alzheimer's disease activities of daily living international scale (ADL-IS). Int Psychogeriatr. 2001;13(2):163-181.

[175] Diehl M, Willis SL, Schaie KW. Everyday problem solving in older adults: observational assessment and cognitive correlates. Psychol Aging. 1995;10(3):478-491.

[176] Fisher AG. AMPS: assessment of motor and processing skills. Vol. 1: development, standardization and administration manual. 5th ed. Ft. Collins, CO: Three Star Press; 2003.

[177] Rosenblum S. The development and standardization of the Children Activity Scales (ChAS-P/T) for the early identification of children with Developmental Coordination Disorders. Child Care Health Dev. 2006;32(6):619-632.

[178] Saidel-Goley IN, Albiero EE, Flannery KA. An evaluation of nonclinical dissociation utilizing a virtual environment shows enhanced working memory and attention. Cyberpsychol Behav Soc Netw. 2012;15(2):112-116.

[179] Cao $X$, Douguet AS, Fuchs $P$, et al. Designing an ecological virtual task in the context of executive functions: a preliminary study. Proceedings of the 8th International Conference on Disability, Virtual Reality and Associated Technologies; 2010. p. 71-78.

[180] Rocke K, Hays P, Edwards D, et al. Development of a performance assessment of executive function: the Children's Kitchen Task Assessment. Am J Occup Ther. 2008;62(5): 528-537.

[181] Downes M, Berg C, Kirkham FJ, et al. Task utility and norms for the Preschool Executive Task Assessment (PETA). Child Neuropsychol. 2018;24(6):784-798.

[182] Josman N, Goffer A, Rosenblum S. Development and standardization of a "do-eat" activity of daily living performance test for children. Am J Occup Ther. 2010;64(1): 47-58.

[183] Chevignard MP, Catroppa C, Galvin J, et al. Development and evaluation of an ecological task to assess executive functioning post childhood TBI: the children's cooking task. Brain Impairment. 2010;11(2):125-143.

[184] Burns T, Mortimer JA, Merchak P. Cognitive Performance Test: a new approach to functional assessment in Alzheimer's disease. J Geriatr Psychiatry Neurol. 1994;7(1): 46-54.

[185] Hartman-Maeir A, Harel H, Katz N. Kettle test-a brief measure of cognitive functional performance. Reliability and valdity in stroke rehabilitation. Am J Occup Ther. 2009;63(5):592-599. 
[186] Poole JL, Sadek J, Haaland KY. Meal preparation abilities after left or right hemisphere stroke. Arch Phys Med Rehabil. 2011;92(4):590-596.

[187] Baum C, Edwards DF. Cognitive performance in senile dementia of the Alzheimer's type: the Kitchen Task Assessment. Am J Occup Ther. 1993;47(5):431-436.

[188] Chevignard MP, Taillefer C, Picq C, et al. Ecological assessment of the dysexecutive syndrome using execution of a cooking task. Neuropsychol Rehabil. 2008;18(4):461-485.

[189] Buxbaum LJ, Schwartz MF, Carew TG. The role of semantic memory in object use. Cognitive Neuropsychology. 1997; 14(2):219-254.

[190] Giovannetti T, Libon DJ, Buxbaum LJ, et al. Naturalistic action impairments in dementia. Neuropsychologia. 2002; 40(8):1220-1232.

[191] Tanguay AN, Davidson PS, Guerrero Nuñez KV, et al. Cooking breakfast after a brain injury. Front Behav Neurosci. 2014;8:272.

[192] Kosowicz M, MacPherson SE. Improving multitasking assessment in healthy older adults using a prop-based version of the Breakfast task. Appl Neuropsychol Adult. 2017;24(3):252-263.

[193] Doherty TA, Barker LA, Denniss R, et al. The cooking task: making a meal of executive functions. Front Behav Neurosci. 2015;9:22

[194] Akerman Frid S, Josman N, Endevelt R. Development and standardization of the "Let's Shop" questionnaire: an assessment of shopping habits and executive functions in people with obesity. Food Sci Nutr. 2017;5(3):446-453.

[195] Carelli L, Morganti F, Weiss PL, et al. A virtual reality paradigm for the assessment and rehabilitation of executive function deficits post stroke: Feasibility study. 2008. Virtual Rehabilitation; 2008.

[196] Cook LG, Chapman SB, Levin HS. Self-regulation abilities in children with severe traumatic brain injury: a preliminary investigation of naturalistic action. NeuroRehabilitation. 2008;23(6):467-475.

[197] Todd JA, Anderson VA, Lawrence JA. Planning skills in head injured adolescents and their peers. Neuropsychol Rehabil. 1996;6(2):81-99.

[198] Shanahan L, McAllister L, Curtin M. The party planning task: a useful tool in the functional assessment of planning skills in adolescents with TBI. Brain Inj. 2011;25(11): 1080-1090.

[199] Roy A, Allain P, Roulin JL, et al. Ecological approach of executive functions using the Behavioural Assessment of the Dysexecutive Syndrome for Children (BADS-C): developmental and validity study. J Clin Exp Neuropsychol. 2015;37(9):956-971.

[200] Weiner NW, Toglia J, Berg C. Weekly Calendar Planning Activity (WCPA): a performance-based assessment of executive function piloted with at-risk adolescents. Am J Occup Ther. 2012;66(6):699-708.
[201] Gioia G, Isquith P, Guy S, et al. Behavior Rating Inventory of Executive Function. Lutz (FL): Psychological Assessment Resources; 2003.

[202] Gioia GA, Espy KA, Isquith PK. 2015. BRIEF-2. Evaluación Conductual de la Función Ejecutiva. Adaptado a la población española por. In: Maldonado-Belmonte MJ, Fournier del Castillo MC, Martínez-Arias R, GonzálezMarqués J, Espejo-Saavedra Roca JM, Santamaría P, editors. Madrid: TEA ediciones; 2017.

[203] Holst $Y$, Thorell LB. Adult executive functioning inventory (ADEXI): validity, reliability, and relations to ADHD. Int J Methods Psychiatr Res. 2018;27(1):e1567.

[204] Schneider E, Rosenblum S. Development, reliability, and validity of the My Child's Play (MCP) questionnaire. Am J Occup Ther. 2014;68(3):277-285.

[205] Lifshitz N, Josman N. Development of a questionnaire for assessing the student's organizational abilities: establishing reliability and Validity. Israeli J Occup Ther. 2006;15: $\mathrm{H} 5-\mathrm{H} 29$.

[206] Frisch C, Rosenblum S. Reliability and validity of the executive function and occupational routines scale (EFORTS). Res Dev Disabil. 2014;35(9):2148-2157.

[207] Romero-Ayuso D, Jorquera-Cabrera S, Segura-Fragoso A, et al. Assessment of sensory processing and executive functions in childhood: development, reliability, and validity of the EPYFEI. Front Pediatr. 2018;6:71.

[208] Chubarov E, Sommerfeld E, Hermesh H, et al. Dynamic occupation assessment of executive function in adolescents with schizophrenia spectrum disorders: an initial report. Eur Psychiatry. 2015;30(8):894-899.

[209] Wilson BA, Alderman N, Burgess PW, et al. Behavioural assessment of the dysexecutive syndrome. Bury, St. Edmunds 1996.

[210] Stout JC, Ready RE, Grace J, et al. Factor analysis of the frontal systems behavior scale (FrSBe). Assessment. 2003; 10(1):79-85.

[211] Pedrero-Pérez EJ, Ruiz-Sánchez de León JM, MoralesAlonso $S$, et al. [Prefrontal clinical symptoms in daily living: screening assessment by means of the short Prefrontal Symptoms Inventory (PSI-20)]. Rev Neurol. 2015;60(9):385-393.

[212] Montgomery J, Storey K, Post M, et al. The use of auditory prompting systems for increasing independent performance of students with autism in employment training. Int J Rehabil Res. 2011;34(4):330-335.

[213] Spikman JM, Boelen DH, Lamberts KF, et al. Effects of a multifaceted treatment program for executive dysfunction after acquired brain injury on indications of executive functioning in daily life. J Int Neuropsychol Soc. 2010; 16(1):118-129.

[214] Parsons TD, Bowerly T, Buckwalter JG, et al. A controlled clinical comparison of attention performance in children with $A D H D$ in a virtual reality classroom compared to standard neuropsychological methods. Child Neuropsychol. 2007;13(4):363-381. 